\title{
Avian models and the study of invariant asymmetry: how the chicken and the egg taught us to tell right from left
}

\author{
ANNE H. MONSORO-BURQ ${ }^{1,2,3}$ and MICHAEL LEVIN*,4 \\ ${ }^{1}$ Univ. Paris Sud, Université Paris Saclay, CNRS UMR 3347, INSERM U1021, F-91405, Orsay, France, \\ 2Institut Curie Research Division, PSL Research University, CNRS UMR 3347, INSERM U1021, France, \\ ${ }^{3}$ Institut Universitaire de France, Paris, F-75005, France and \\ ${ }^{4}$ Allen Discovery Center at Tufts University, Medford, MA, USA
}

\begin{abstract}
While the external vertebrate body plan appears bilaterally symmetrical with respect to anterior-posterior and dorsal-ventral axes, the internal organs are arranged with a striking and invariant left-right asymmetry. This laterality is important for normal body function, as alterations manifest as numerous human birth defect syndromes. The left-right axis is set up very early during embryogenesis by an initial and still poorly understood break in bilateral symmetry, followed by a cascade of molecular events that was discovered 20 years ago in the chick embryo model. This gene regulatory network leads to activation of the pitx2 gene on the left side of the embryo which ultimately establishes asymmetric organogenesis of the heart, gut, brain, and other organs. In this review, we highlight the crucial contributions of the avian model to the discovery of the differential transcriptional cascades operating on the Left and Right sides, as well as to the physiological events operating upstream of asymmetric gene expression. The chick was not only instrumental in the discovery of mechanisms behind left-right patterning, but stands poised to facilitate inroads into the most fundamental aspects that link asymmetry to the rest of evolutionary developmental biology.
\end{abstract}

KEY WORDS: left-right, laterality, chirality, embryogenesis, chick, sonic hedgehog, nodal, bioelectricity, gap junction

\section{Introduction}

One of the most immediately obvious features of the vertebrate body plan is its overall bilateral symmetry: most animals are constructed of two halves which are mirror images of each other, joined at a central midplane. This architecture is established extremely early as a fundamental feature of embryogenesis. However, subsequent development reveals a fascinating and progressive departure from left-right symmetry: numerous structures develop with a marked and consistent difference in their shape or placement with respect to the midplane. Perhaps the most remarkable aspect of animal anatomy is that organs such as the heart, gut, liver, brain, etc. are not only asymmetric, but are consistently so. All normal individuals have these organs on their correct respective side, exhibiting not simply asymmetry but a very strong bias of sidedness relative to the anterior-posterior and dorso-ventral axes.

\section{The fundamental puzzle of left-right (LR) asymmetry}

In fact, biological systems including bacteria (Mendelson and Keener, 1982), slime molds (Dimonte et al., 2016), plants (Hashimoto, 2002), and individual vertebrate cells in culture (Chen et al.,
2012, Xu et al., 2007) can all tell left from right. Here, we discuss the mechanisms that enable animal embryos to create consistently asymmetric internal organs, focusing on the contributions of avian models to this question. Minor deviations from perfect symmetry (e.g., subtle random differences in the lengths of the legs for example) are called fluctuating asymmetry (arising from developmental noise), and are not discussed here. True left-right asymmetry is a phenomenon that is far more difficult to understand. In 3D space, an organism breaks symmetry once to set up the head-tail axis, and places the sense organs at the end that will encounter things first, as the animal moves forwards. Together with the AP axis, an early embryo also acquires a dorso-ventral axis. As long as AP and DV axes are orthogonal, any choice of planes will do. But, having fixed the AP and DV axes, there is no longer any choice about the $L R$ axis - the $L$ and $R$ directions are fixed. How does an embryo determine which direction is which, when, macroscopically, nothing distinguishes left from right? One can appreciate the problem by visualizing the difficulty of explaining to someone, over a telephone

Abbreviations used in this paper: HH, Hamburger-Hamilton developmental stage; LR, left-right.

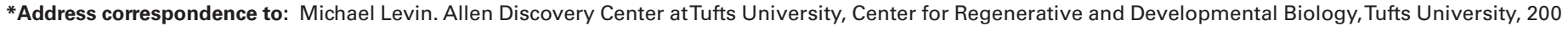
Boston Avenue, suite 4600, Medford, MA 02155-4243, USA. Tel: +1 617627 6161. Fax: +1 6176276121. E-mail: michael.levin@tufts.edu 
connection, which one is meant by "Left hand" (without reference to an already shared chiral object). Thus, the consistent establishment of invariant left-right asymmetry in all normal vertebrate embryos is a truly profound problem.

\section{Steps to achieving LR asymmetry}

Correct LR patterning requires several elements (Fig. 1). First, symmetry breaking - the $L$ and $R$ sides must be made different in some way. Then, the asymmetry has to be correctly oriented (so that the $L$ and $R$ sides are not merely different, but the $L$ features are always on the left side of the organism). This information has to be propagated from the cellular level to large cell fields. Work in several (non-avian) species has revealed that these processes involve an amplification of cellular chirality (knowing which direction is $L$ or $R$ ) into multicellular asymmetry (position along the L/R axis). Finally, this information needs to be interpreted by organ primordia to allow them to perform asymmetric morphogenesis. The flat blastoderm of the chick and amenability to surgical and molecular-genetic techniques has enabled it to play an instrumental role in revealing 1) the molecular genetics of asymmetric gene expression comprising the middle part of the pathway, 2) key elements of the upstream amplification process, and 3) the biophysics involved in heart and gut asymmetric morphogenesis.

\section{The importance of LR asymmetry}

LR asymmetry is a difficult puzzle; it is no coincidence that the first molecular inroads into unraveling this aspect of development came much later than insights into the AP and DV axes. Consistent asymmetry raises a host of questions in cell and evolutionary biology: why are we asymmetric at all? And even if asymmetric,

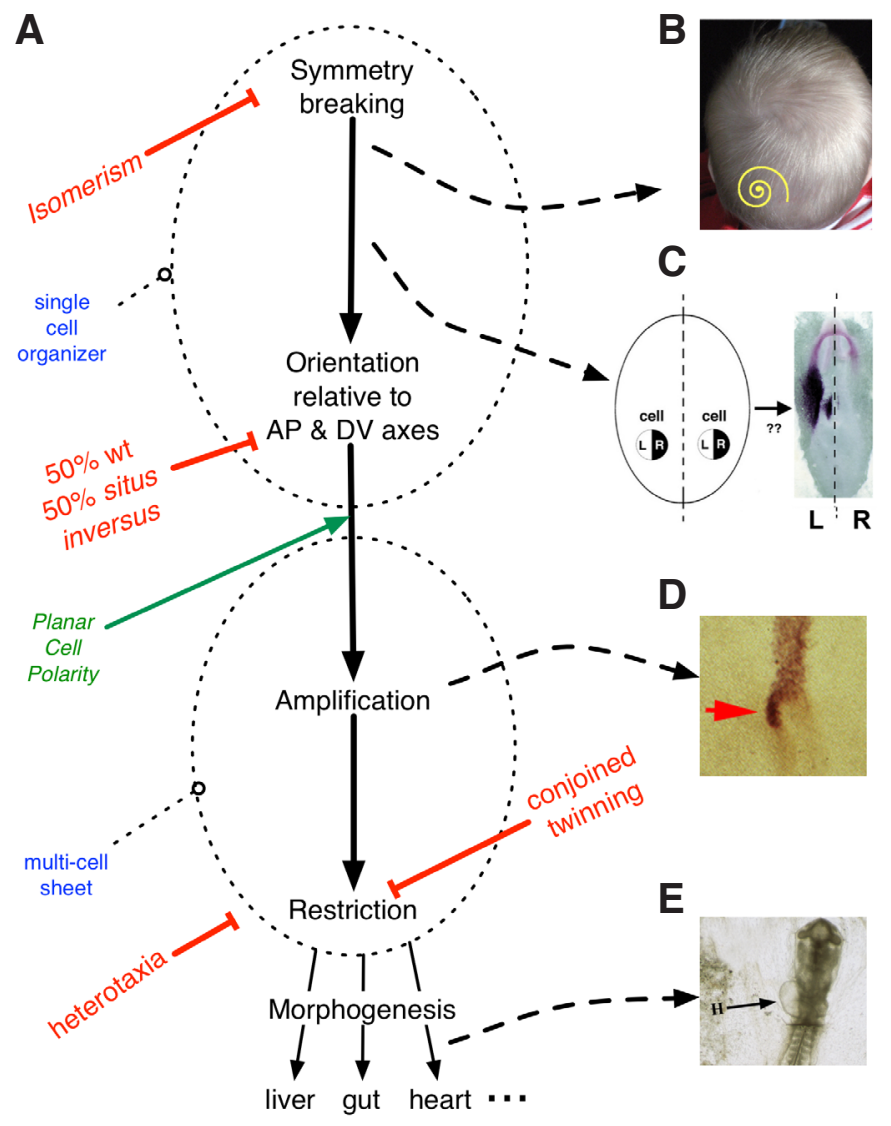

why always in the same direction and not randomly oriented? Interestingly, the lessons learned about LR patterning (discussed below) are of value not only in explaining asymmetry: as it turns out, the mechanisms of LR asymmetry are a paradigm case of multi-scale biological integration. The study of asymmetry reveals to us how living systems can convert molecular-level information into large-scale anatomy.

Aside from these fundamental issues, LR asymmetry has a more practical side: clinical relevance to a number of human syndromes - primary defects of laterality, as well as other syndromes with lateralized presentations in the human patient. There are several ways for asymmetry to go awry: mirror image reversal, loss of asymmetry or randomization of individual organs' sidedness.

\section{Human primary laterality syndromes}

From the outside, adult human bodies generally look symmetrical between left and right, despite minor random variations between individuals. From the inside, however, numerous organs are positioned with a strong bias towards one side. This is the case for unpaired organs: most of the heart, spleen, pancreas and stomach are located on the left side, while most of the liver and gall bladder are found on the right side (Fig. 2). These organs are first formed symmetrically, at the embryo midline, and then undergo complex morphogenesis that positions them on one side. Some major blood vessels, such as aortas, are initiated symmetrically, then undergo by a regression phase on one side. Similarly, many paired organs also display asymmetrical development or looping, such as brain hemispheres, lungs, and gut. This left-right organization, which is the most commonly found in humans, is called situs solitus. Laterality disorders have a global incidence of 1/8-15,000 in humans (Orphanet website; Catana and Apostu, 2017). Full left-right reversal of internal organ organization, called situs inversus (or situs inversus totalis), has a rare incidence of

Fig. 1. Conceptual phases of left-right (LR) patterning and their subsequent readouts. (A) $L R$ symmetry breaking requires that a midline be established, and one side be made different from the other. This difference needs to be consistently oriented within the population. The information needs to be amplified and transmitted to multiple organ systems during organogenesis; midline structures must restrict side-specific signals from crossing over. Lack of coordination results in heterotaxia, where individual organs make independent decisions, resulting in a spectrum of random placement within an affected cohort. Red arrows indicate phenotypes arising from disruption of each step. (B) Hair whorls reveal the presence of chirality, a fundamental early step of asymmetry not requiring a midline, and its link to planar polarization of many later tissues such as skin and hair (Aw and Levin, 2009). In monozygotic twins, such hair whorls are mirror images (Golbinetal., 1993, Klar, 2003), revealing a link to symmetry-breaking events occurring during the earliest cell cleavages. (C) During the orientation and amplification phases occurring after the embryonic midline has been established, cells must convert intracellular knowledge of direction along the $L R$ axis or chirality (the same in all cells) into position relative to the midline (different in L vs. R cells), here illustrated by the expression of Nodal in lateral plate cells only on the left side of the chick embryo (dark purple is Nodal, light pink is Nkx2.5, taken from cover of Levin et al. (1995). (D) The amplification of primary events results in the asymmetric expression of genes like Sonic hedgehog, shown here on the left side of Hensen's node (taken from Levin et al., 1995). (E) Asymmetric cues feed into morphogenesis of organs such as the heart tube (taken from Levin et al., 1995). Figure modified after (Vandenberg and Levin, 2009). 


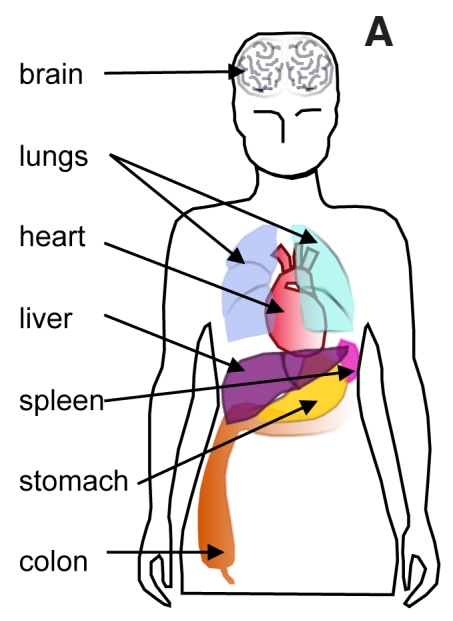

situs solitus

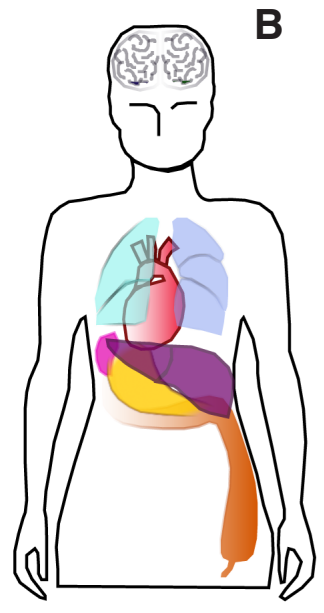

situs inversus

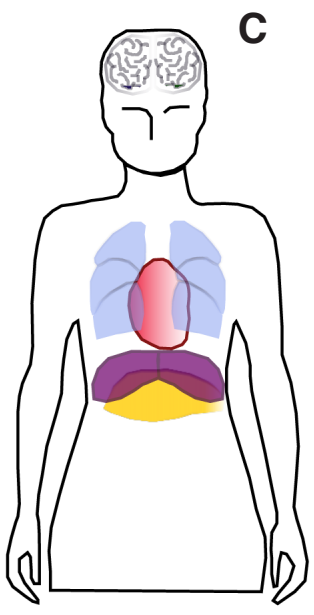

right isomerism

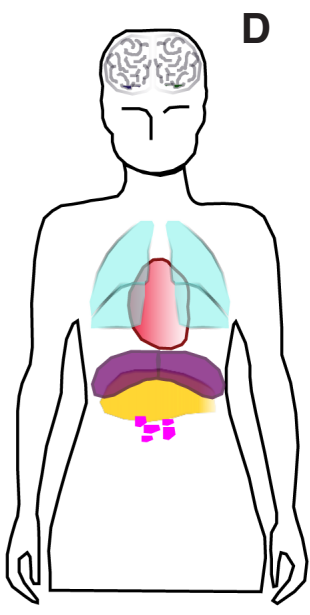

left isomerism

Fig. 2. Laterality in humans: situs solitus and some situs alterations. Many organs are arranged asymmetrically along the $L R$ axis within the human body cavity. The normal arrangement (A), called situs solitus, includes the left lung with two lobes whereas the right lung has three, the heart pointing to the left side, the stomach and spleen on left while the liver is mostly on the right body side, as well as gut coiling in counterclockwise direction. Complete inversion of this arrangement (B), called situs inversus totalis, usually does not cause physiological malfunctions. In contrast, the mirror duplication of the right (C) or left-(D) sided organs, named isomerism, cause severe pathological conditions. Right isomerism, also known as asplenia syndrome, exhibits duplication of the right heart chamber, of the right lung, and of the liver, loss of spleen, abnormal positioning of the stomach. Left isomerism results in polysplenia syndrome, with multiple non-functional small spleen-like structures, often associated with gastrointestinal abnormal rotation and cardiac anomalies. Interestingly, the defects in these internal organs organization do not seem correlated to brain laterality modifications. The organs are color-coded for clarity and the schemes are simplified to show only the main features, as a large spectrum of anomalies is observed in patients.

$1 / 8-25,000$, which is likely underestimated since most patients are asymptomatic (Casey, 1998, Peeters and Devriendt, 2006). Other laterality disorders, grouped under the name of heterotaxy (from the Greek "other arrangement") or situs ambiguus, cause severe medical condition, including organ malformations and functional disorders. Heterotaxy includes left or right isomerism, when the left-sided or right-sided organs respectively, are mirrored on the opposite side, and all other configurations of random relative positioning of internal organs. These defects in laterality, resulting in aberrant relationships between organs, cause complex congenital heart disease in $80 \%$ of the patients with heterotaxy (such as transposition of the great arteries, various ventricular defects, atrioventricular septum malformations, defective pulmonary venous connections) (Peeters and Devriendt, 2006, Ramsdell, 2005). The patients with heterotaxy represent $3 \%$ of total congenital heart defects (CHD) in human. In contrast to $80 \%$ of $\mathrm{CHD}$ in patients with heterotaxy, only 3-9\% patients with situs inversus present $\mathrm{CHD}$, which is still higher incidence that in the normal situs solitus situation ( $\mathrm{CHD}$ in $0.6 \%$ ), but means that total reversal of organ positioning results in a relatively normal physiological situation (Peeters and Devriendt, 2006).

In the brain, the anatomical signs of laterality are more subtle, and mainly found in areas involved in language processing (Duboc et al., 2015). Interestingly, brain laterality seems independent from visceral organ arrangement, as patients with situs inversus have the same language lateralization as situs solitus individuals (Kennedy et al., 1999).

Interestingly, laterality is a feature of other body systems that do not display overt anatomical asymmetry. A number of syndromes are present unilaterally in paired structures like the limbs (Smith et al., 1979), face, or hips (Delaney and Boyd, 2007, Paulozzi and Lary, 1999). Even cancer incidence (Robichaux et al., 2015, Sandson et al., 1992; Wilting and Hagedorn, 2011) and immune response (Dane et al., 2001; Meador et al., 2004) exhibit invariant asymmetries, revealing that left-right patterning is embedded in body form and function far deeper than just the positioning of asymmetric organs.

\section{Human syndromes with disorders of lateralization}

Human laterality defects are found in diverse forms: they include familial or sporadic forms, with isolated or syndromic phenotypes. The genetic inheritance can involve autosomal recessive or X-linked recessive, or autosomal dominant transmission (Casey, 1998). About 230 genes and genetic phenotypes have been associated to left-right asymmetry anomalies (45 OMIM entries for heterotaxy and 186 OMIM entries for situs inversus, June 2017).

Situs inversus is well-defined phenotype, with autosomal recessive transmission. Numerous human phenotypes of situs inversus are associated with primary cilia dysfunction. Described in 1933, Kartagener Syndrome (OMIM \# 244400) associates situs inversusto primary cilia dyskinesis (PCD). It is belongs to the familial Immotile Cilia Syndromes (ICS), with dyskinesic/immotile primary cilia and flagella caused by defective dynein arm (Mitchison et al., 2012). ICS patients present malfunction of upper and lower airways and infertility (Casey, 1998, Fretzayas and Moustaki, 2016). Half of the ICS patients harbor situs inversus, while situs ambiguus is rare (6.7\%; Kennedy et al., 2007), suggesting a randomized lateralization in ICS. Other familial situs inversus, not associated to ICS, have sometimes been reported, also with autosomal recessive transmission (Chib et al., 1977, Cockayne, 1938, Corcos et al., 1989, Kosaki and Casey, 1998, Mital et al., 1974).

Heterotaxia encompasses a broad spectrum of clinical fea- 
tures, and it is unclear if isolated cardiac malformations, or other isolated visceral organ abnormalities, relate to laterality defects. The "classical" situs ambiguus associates cardiovascular defects to visceral organ malformations. Familial cases of situs ambiguus have been described in children born from consanguineous parents. Heterotaxy genetic transmission follows either autosomal dominant, or autosomal recessive, or X-linked modalities (Kosaki and Casey, 1998, Zhu et al., 2006). However, most described cases of heterotaxia are likely sporadic, supporting that Mendelian inheritance is not the rule. A recent study suggests, however, after closer phenotypic examination of unaffected individuals in the pedigree, that $10 \%$ of infants with heterotaxy could belong to a family with congenital cardiac defects (Zhu et al., 2006). The identification of the genes associated to situs ambiguus will further aid analyzing the familial history for cases of apparently isolated heterotaxy.

\section{Early steps: asymmetry research prior to molecular work in the chick}

It is somewhat remarkable, given that this is a major body axis, that the total sum knowledge about asymmetry prior to 1995 can be summarized as follows. Some such as Neville (Neville, 1976) had cataloged the numerous consistent asymmetries throughout the animal kingdom, at the level of anatomy and histology; examples (most of which did not turn into molecular model species in the LR field) include beetles that consistently fold one wing under the other, crustaceans with specialized right and left fore-limbs, flatfish that consistently settle on and undergo eye migration to one side, and parasites that lives only on one side of host prawn and shrimp. It was however known from developmental work in sea urchin and frog that the LR axis was probably specified after the anterior-posterior (AP) and dorso-ventral (DV) axes, and is determined with respect to them (McCain and McClay, 1994); early surgical work in chick had identified gastrulation as a sensitive period for affecting heart laterality (Hoyle et al., 1992) - a finding backed up by early rodent studies (Fujinaga and Baden, 1991a). In amphibian (Yost, 1990) and rodent (Fujinaga and Baden, 1991b, Fujinaga et al., 1990) embryonic models, drug experiments had identified a variety of compounds that caused LR inversions, randomizations, or unilateral defects (reviewed in Levin, 1997), but mechanisms were unclear.

Genetic approaches had provided interesting data. Selection attempts for LR asymmetries in Drosophila, in hopes of generating a genetically-tractable mutant, had failed (Tuinstra et al., 1990). However work on molluscs, which undergo chiral spiral cleavage, implicated an unknown cytoplasmic determinant (Freeman and Lundelius, 1982, Murray and Clarke, 1966). Several mammalian mutants were known, which displayed either defects in basic LR patterning or phenotypes that differentially affect the left or right sides of the body (reviewed in Levin, 1997). For example, iv (Hummel and Chapman, 1959) produces racemic offspring (50\% being phenotypically situs inversus), while inv (Yokoyama et al., 1993) mice have $\sim 85 \%$ of the offspring showing mirror image inversions of the internal organs. Mutants such as legless (Schreiner et al., 1993, Singh et al., 1991) exhibit limb phenotypes that are more pronounced on one side of the body. Ironically, it was the chick - a model system amenable to classical embryology but not genetics - that provided the first clues to the molecular basis of invariant LR asymmetry.

\section{Classical data}

Many classical studies have explored L/R patterning prior to the molecular identification of early players of the L/R asymmetry cascade in the late 1990's. In chick embryos, a series of experiments have identified that gastrulation is a critical timing period for L/R axis setting, and that the node (Hensen's node) is a key structure. To study sidedness of heart looping, which orients to the right-hand side in most embryos, Wolpert and colleagues performed delicate heterotopic grafts of left or right precardiac mesoderm during chick gastrulation (Hoyle et al., 1992). In chick, gastrulation takes place during primitive streak elongation, from stage $3+$ to stage 4 , according to Hamburger and Hamilton $(\mathrm{HH})$ staging table (Hamburger and Hamilton, 1951). Later on, gastrulation proceeds posteriorly, along the regressing primitive streak, while neurulation starts anteriorly (Gilbert, 2006). Hoyle et al., thus demonstrated that embryos with bilateral right-sided precardiac mesoderm, taken from stage 4-5HH donor embryos, develop a high proportion of left-sided (inverted) hearts. Moreover, this effect decreases when stage $6 \mathrm{HH}$ precardiac mesoderm is grafted. This striking result matched the critical period identified for mammalian (rat embryos) L/R axis setup, with treatment with an adrenergic agonist (Fujinaga and Baden, 1991b) (see below). Furthermore, Hensen's node displays a clear morphological L/R asymmetry, very transiently between stage $5 \mathrm{HH}$ and $8 \mathrm{HH}$ (subtle asymmetries are even seen at earlier stage $4 \mathrm{HH}$ ), suggesting that node development could be the influenced by early laterality regulators, and that the node could play a role in L/R axis formation (Cooke, 1995, Dathe et al., 2002). Node rotation experiments in chick gastrulas, at either stage $4 \mathrm{HH}$ or stage $5 \mathrm{HH}$, demonstrated that only a stage $5 \mathrm{HH}$ node influenced embryo laterality (PaganWestphal and Tabin, 1998). When the node was rotated at stage $4 \mathrm{HH}$, the $\mathrm{L} / \mathrm{R}$ axis was reset to the normal orientation respective to the embryo, not to the rotated node. This indicated that the node acquires knowledge of the L/R axis at stage $5 \mathrm{HH}$, and that the node can subsequently influence laterality of the embryo (Pagan-Westphal and Tabin, 1998). It also indicated upstream regulation by the surrounding tissues, influencing node L/R patterning prior to stage $5 \mathrm{HH}$. However, these experiments did not indicate the nature or properties of the mechanism nvolved in L/R axis determination.

\section{Avian asymmetries}

The embryonic chick turned out to be pivotal in unraveling these steps. Prior to considering the molecular work, it is helpful to sketch the anatomical and functional asymmetries in this model system. During gastrulation, the organizing center at the tip of the primitive streak, Hensen's node, already exhibits a consistent asymmetry: its right lip is much more prominent than the left and contains a cell condensation connected with the head process (Cooke, 1995, Dathe et al., 2002). Another macroscopic aspect of whole-embryo asymmetry is the process of "turning": the wild-type embryo rotates to its right and lies on its side. There is some correlation between the turning and subsequent heart situs (Waddington, 1937), but these processes are dissociable and can occur in different directions if LR patterning signals are randomized (Hoyle et al., 1992, Levin et al., 1997).

Organogenesis is highly asymmetric; the most obvious example of this is the heart tube, which bends and folds in a stereotypical 
pattern that subsequently sets up the canonical example of asymmetry - the vertebrate heart. This process involves differential properties of cells on the right and left side of the precardiac fields and heart tube itself, including proliferation and traction forces, mediated by cytoskelon and retinoic acid signaling (Latacha et al., 2005, Linask et al., 2003, Linask et al., 2002, Manner, 2004, Simard et al., 2006, Stalsberg, 1969, Tsuda et al., 1996, Yue et al., 2004, Zamir et al., 2003, Zile et al., 2000). Likewise, the profound asymmetry of the viscera involve asymmetric morphogenesis and rotation of the gut tube, now known to be driven by differential extracellular matrix and cell adhesion properties, as well as physical forces transmitted from the mesentery (Branford et al., 2000, Davis et al., 2008, Kurpios et al., 2008, Welsh et al., 2013, Yuan and Schoenwolf, 2000).

In addition to these, most obvious anatomical aspects of asymmetry arising in singular (midline) structures, the chick offers a model for asymmetric development of paired organs. Interestingly, only the left ovary and oviduct persists in normal avian embryos. Useful strains of chickens exist, such as the PNO/DO line, in which the right oviduct persists (Hoshino et al., 2005, Ishimaru et al., 2008, Wakamatsu et al., 2000), providing an opportunity to study the role of programmed cell death and remodeling in the sculpting of asymmetry. The lateralization of paired structures extends

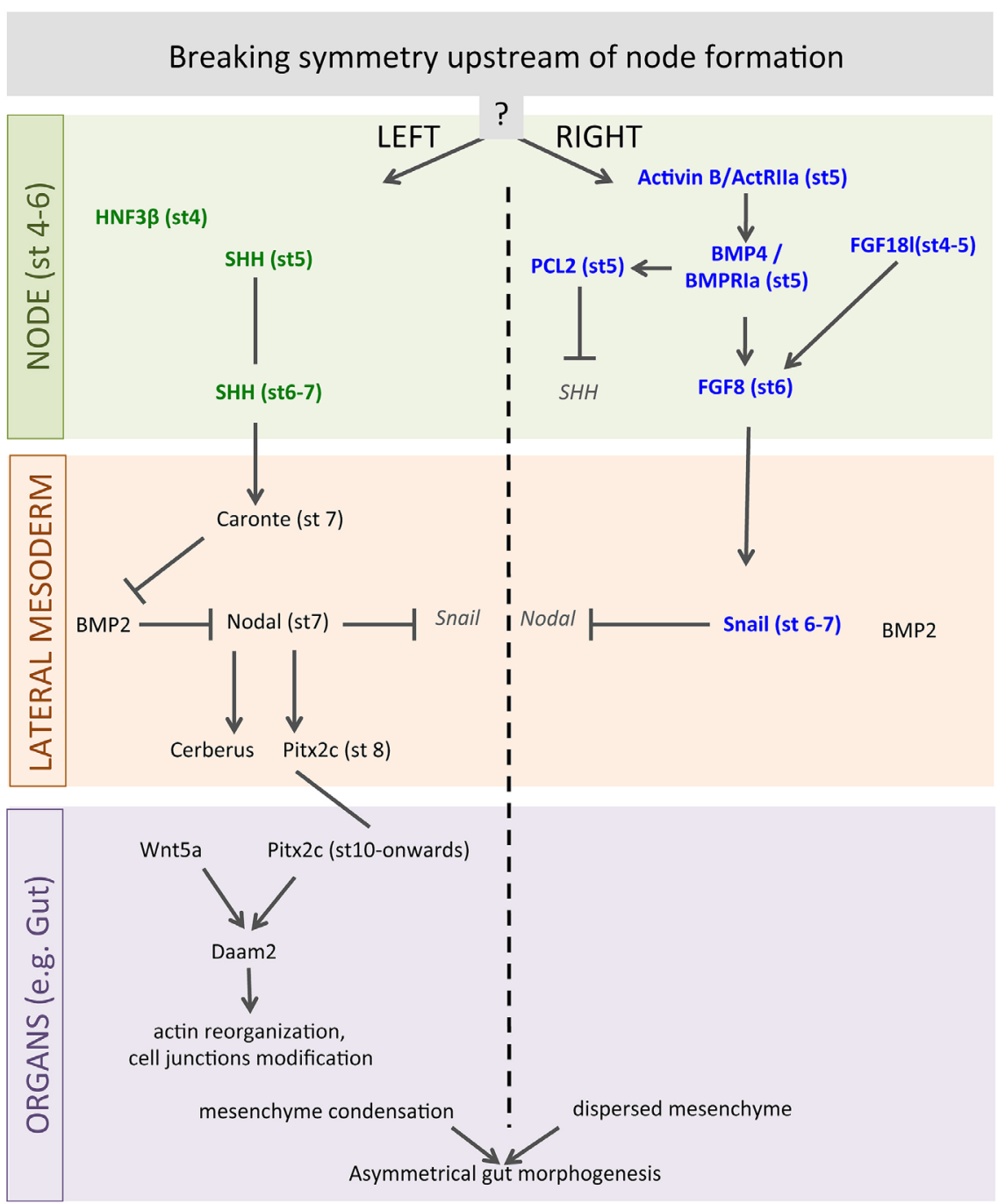

to the anatomy and function of the brain, including connections to the eyes. Chick brain hemispheres have consistently distinct responses to, and provide differential processing of, stimuli mediated by light and even magnetoreception (Rogers, 2008, Rogers et al., 2008, Vallortigara et al., 2001, Vallortigara et al., 1996). This is thought to derive from different light exposure of the left and right eye, driven by the invariant rotation of the embryo which points one eye upward and one down into the darker portion of the egg.

\section{The molecular age}

A breakthrough in the understanding of the molecular basis of left-right asymmetry determination occurred some 20 years ago, with the observation of asymmetrical gene expressions in chick Hensen's node. A series of studies comprising gain and loss of function for various signaling molecules, as well as combined manipulations for phenotypical rescues, has allowed deciphering a left-right asymmetry gene regulatory network (LR-GRN) that can be subdivided into three main steps in chronological order, over a short period of development: establishing stable initial gene asymmetries in the node at the end of gastrulation, relay the asymmetry information to the adjacent mesoderm, propagate and control $\mathrm{L} / \mathrm{R}$ asymmetry during organogenesis. As this LR-GRN involves a complex cascade of genetic activities, those three steps are depicted separately in Fig. 3.

\section{Molecular asymmetries pattern left from right in the node, between stages $4 \mathrm{HH}$ and $6 \mathrm{HH}$}

As mentioned above, initial asymmetry in Hensen's node morphology can be detected as early as the stage of fully extended primitive streak (stage $4 \mathrm{HH}$ ), suggesting that breaking of bilateral symmetry has already taken place at that early stage (Dathe et al., 2002). From 1995 onwards, there was a period of active discovery of asymmetrical gene expressions in the node. Early Hnf3b expression was found transiently enhanced on the left side of the stage $4 \mathrm{HH}$ node. While symmetrically expressed until stage $4 \mathrm{HH}$, at stage $5 \mathrm{HH}$ (nascent notochord stage), sonic hedgehog (shh) was detected on the left side of the node and maintained this expression pattern until stage $7 \mathrm{HH}$ (3-somites stage) (Levin et al., 1995). In contrast, activin receptor Ila was expressed on the right side of the primitive streak just prior to stage $4 \mathrm{HH}$, then on the right side of the node at stage $5 \mathrm{HH}$ (Levin et al., 1995). At stage $5 \mathrm{HH}$, shh and

Fig. 3. The molecular cascade of asymmetricallyexpressed genes. The temporal sequence of the regulatory genetic interactions starting in the node is described as three main steps: molecular events within the node, transmission of laterality information to the adjacent lateral mesoderm, and control of organogenesis, with gut morphogenesis chosen as an example. Details on gene activation and function of each factor are described in the text. The initial symmetry breaking events acting upstream of this $L R-G R N$ are described in Figure 5 and text. 
activin receptor Ila asymmetrical gene expression were found in the superficial layer of the node, which both contribute later to the notochord (Levin et al., 1995). The initial left-sided expression of shh is further stabilized by inhibiting signals on the right side of the node, since, for example, blocking right-sided BMP signaling at stage $5 \mathrm{HH}$ results in bilateral shh expression at stage $6 / 7 \mathrm{HH}$ (Monsoro-Burq and Le Douarin, 2001). Indeed, on the right side of the node, a molecular cascade including early Activin signals triggers BMP signaling, which in turn activates FGF signals and blocks right-sided activation of shh (Monsoro-Burq and Le Douarin, 2000, Monsoro-Burq and Le Douarin, 2001). In addition, early expression of fgf18 (from stage 4 to $5+\mathrm{HH}$ ) is also involved in the right-sided expression of $f g f 4$ and $f g f 8$ at stage $6 \mathrm{HH}$ (Boettger et al., 1999, Ohuchi et al., 2000, Shamim and Mason, 1999). Finally, polycomb-like PCL2 transcriptional repressor could mediate the repressive action of these right-sided signals on shh expression (Wang et al., 2004). Hence, molecular asymmetries are initiated and stabilized by coordinated and antagonistic signaling cascades on each side of the node (Fig. 3).

\section{Left-sided information is transmitted to the lateral mesoderm around stage 7-8H}

At the first somite stages, several markers identify left from right in the mesoderm lying adjacent to the node: on the left, caronte, nodal(chick nodal-related 1, cNR-1) and pitx2 appear around stage $7 \mathrm{HH}$, while snai1 (chick-related snail, $c S n R$ ) marks the mesoderm on the right (Isaac et al., 1997, Levin etal., 1995, Rodriguez Esteban et al., 1999, St Amand et al., 1998, Yokouchi et al., 1999, Yoshioka et al., 1998). SHH, on the left of the node, activates caronte (a member of DAN-Cerberus BMP antagonists family), in the lateral plate mesoderm. Caronte antagonizes BMP signaling asymmetrically, resulting in nodal activation on the left (Rodriguez Esteban et al., 1999, Yokouchi et al., 1999). In turn, Nodal and Lefty-1 trigger cerberus and pitx2expression (Levin et al., 1995, Pagan-Westphal and Tabin, 1998, Yoshioka et al., 1998, Zhu et al., 1999). On the right side of the embryo, Activin and FGF8 signals activate snai1 in the mesoderm while SHH and nodal repress it (Boettger et al., 1999, Isaac et al., 1997, Patel et al., 1999). Snai1 further prevents ectopic activation of pitx 2 on the right side of the embryo (Patel et al., 1999). All these experimental manipulations result in heart situs during later organogenesis (Boettger et al., 1999, Isaac et al., 1997, Levin et al., 1995, Rodriguez Esteban et al., 1999). Together, this series of studies highlights the transmission of left information from the node to the mesoderm (Fig. 3), by nodal and pitx2activation, active repression of the left-sided gene expressions on the right side. In addition, elegant experiments in early mouse embryos have shown that Lefty-2 prevents the diffusion of Nodal signals towards the right side of the embryo (Meno et al., 2001). Furthermore, among other less well-explored cellular parameters, cell-cell adhesion via N-cadherin may influence L/R patterning by regulating pitx2 and snai1 expression (Garcia-Castro et al., 2000).

\section{Pitx2 from the mesoderm controls asymmetrical organogenesis}

A landmark study, using several vertebrate model organisms, has demonstrated the pivotal role of Pitx2 in the transmission of $\mathrm{L} / \mathrm{R}$ information during organogenesis and embryonic rotation. In addition to its expression in the left-side lateral mesoderm around stage $8-9 \mathrm{HH}$, pitx2 is also expressed on the left side of the heart from stage $10 \mathrm{HH}$. During organogenesis, pitx2 is found asymmetrically expressed in the digestive tract and in branchial arches. Misexpression of Pitx2 in chick and frog embryos resulted in heart and embryo turning side defects (Ryan et al., 1998). This study thus placed Pitx2 function as central in the LR-GRN (Fig. 3). Pitx2 is a bicoid-like homeodomain transcription factor, which seems to be active via its N-terminal part (isoform Pitx2c; Simard et al., 2009). Mutations in human Pitx2 have been related to $\mathrm{CHD}$ in patients (Yuan et al., 2013). However, its transcriptional targets involved in organ laterality control were poorly known, until the discovery of asymmetrical WNT signaling in the dorsal mesentery, responsible for asymmetric midgut looping (Welsh et al., 2013). Daam2, regulated by Pitx2 and asymmetrical Wnt signaling in the dorsal mesentery, interacts

Fig. 4. Conjoined twins: laterality defects explained by the left-right (LR) pathway. The asymmetric gene cascade, including Activin Receptor $2 B$ (A), Sonic hedgehog (B), and Nodal (C) helped explain the previously mysterious observation that one of two laterally-conjoined twins (schematized in D) would exhibit laterality disturbances. The model based on ectopic diffusion of asymmetric gene products such as Sonic hedgehog onto the right side of one of the embryos from its neighbor matched human data (Levin et al., 1996) and was directly tested in chick twins, correctly predicting the ectopic induction of Nodal on the right side of the left twin (F). 
with the cell junctions and cell cytoskeleton, thus affecting cell adhesion and behavior (Welsh et al., 2013). This study highlights how asymmetrical gene expression, controlled by Pitx2, results in asymmetrical organogenesis.

In parallel, specific mechanisms buffer the LR-GRN cascade action, during symmetrical organ formation: during somitogenesis, retinoic acid signaling is required for the formation of bilaterally symmetrical somites (Vermot and Pourquie, 2005).

\section{Conjoined twins - explaining human birth defects}

The chick system also enabled a good example of the use of basic developmental genetics to illuminate problems in human medicine. It had long been noticed that inversions of various organs often occur in the context of human conjoined twins (Aird, 1959, Cuniff etal., 1988, Torgersen, 1950). Classical studies also observed spontaneous and experimentally-induced twins in frog, armadillo, and fish embryos: frequent laterality defects affect one of the conjoined twins usually the one positioned on the right side (Morrill, 1919, Newman, 1916, Peeters and Devriendt, 2006, Schwind, 1934, Spemann and Falkenberg, 1919). An explanation for this fact was unknown, despite the fact that almost a century ago, the association between twinning and asymmetry had not escaped the notice of the giants of developmental biology (Mangold, 1921, Spemann and Falkenberg, 1919). These observations suggested that the left twin has an influence on the right-hand side twin, possibly via the action of long-range diffusible molecules. This observation has triggered early works using various pharmacological agents, from simple chemicals such as cadmium to complex agonists/antagonists (see below). An understanding of the molecular determinants of $L$ and $\mathrm{R}$ identity provided a ready explanation for what is happening when two embryonic fields are conjoined (Fig. 4): the left-specific secreted signaling molecules (such as Nodal) can leak over and affect the right side of the adjacent twin. The predictions of this model were validated against chick experiments using induced twins, and the geometric requirements for mutual arrangement of the primary axes (that could allow side-by-side leak-over of signals) provided an explanation for why certain classes of human twins exhibit laterality disturbances and others do not (Levin et al., 1996).

Fig. 5. Physiology: mechanisms upstream of asymmetric gene expression. Upstream of asymmetric gene expression lies a system of physiological signals by means of which the $L$ and $R$ sides coordinate their identity. (A) In a normal cultured chick embryo, the two sides develop correct identity, shown here via the left-sided expression (purple stain) of Nodal. (B) When only the right side is cultured (left lateral tissues removed), its identity is randomized, often exhibiting inappropriate expression of Nodal. (C) Likewise, when the left side is cultured alone, its identity is randomized, often exhibiting a failure to turn on Nodal. Subsequent work (Levin and Mercola, 1999) revealed that a system of gap junctional channels (D) is encoded by genes like Connexin 43, expressed in a circumferential pattern around the nascent streak (E) (white arrowhead reveals zone of isolation in the streak). Interference with the circumferential path, either by knockdown of $\mathrm{C} \times 43$ or single slits in the blastoderm interfering with the long-range current path, randomize asymmetry, suggesting a model in which some $L R$ morphogen is transported intracellularly across the blastoderm through the circumferential gap junctional path (Levin and Nascone, 1997). Such movement requires motive force, which could be provided by the observed voltage gradient (Levin et al., 2002) created by differential resting potentials generated at the $L$ and $R$ sides of the st. $2(\mathbf{G})$ and st. 3-4 $\mathbf{( H )}$ primitive streak (red stain indicates depolarized cells, revealed by voltage-sensitive fluorescent dye; black arrowhead indicates developing Hensen's node).

\section{Upstream of asymmetric gene expression}

\section{Transcription can't tell left from right: events upstream of asymmetric gene expression}

While experiments in the chick helped identify a cascade of leftand right-specific transcripts that ultimately dictated the sidedness of the internal organs, this left a major puzzle. Whatever turns out to be the very first asymmetrically-expressed gene, what makes that transcript only be expressed on its correct side? The work of chasing each asymmetric gene upstream to see what induces it cannot go on forever; because transcription alone cannot tell left from right, some other aspect of physics or physiology has to occur upstream of, and instruct, the first asymmetric gene in the LR pathway cascade (Fig. 5).

In 1999, the chick model facilitated the identification of the first such component. The distinct, mutually-repressive programs on the left and right sides of the embryo suggested that the $L$ and $R$ sides
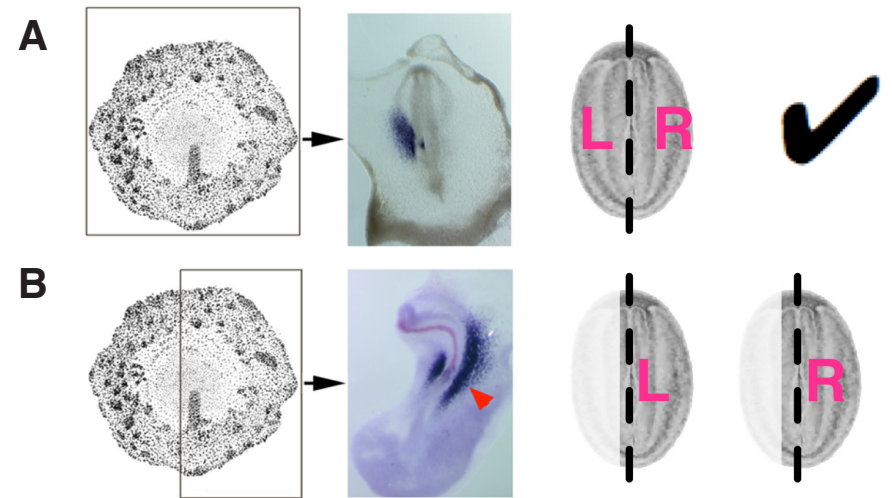

C
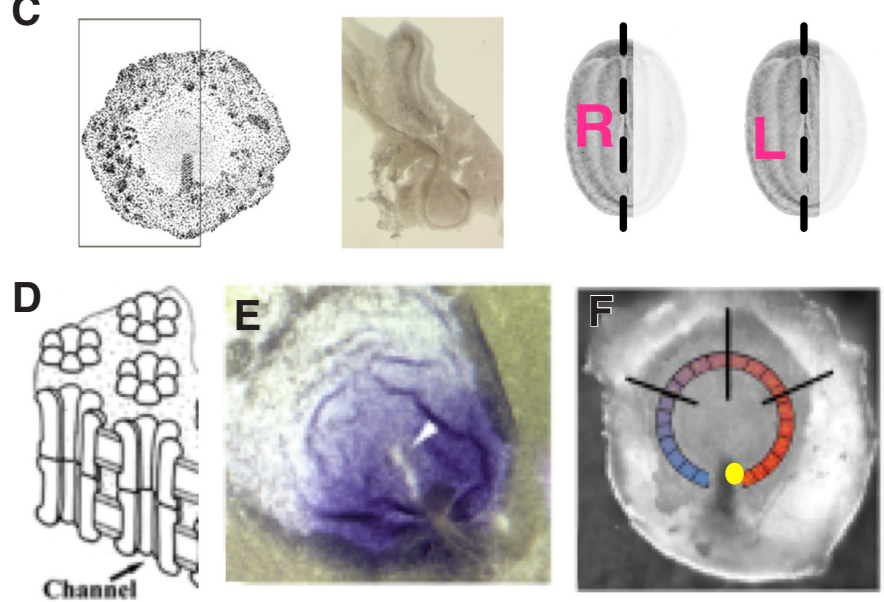

(<1 kD)
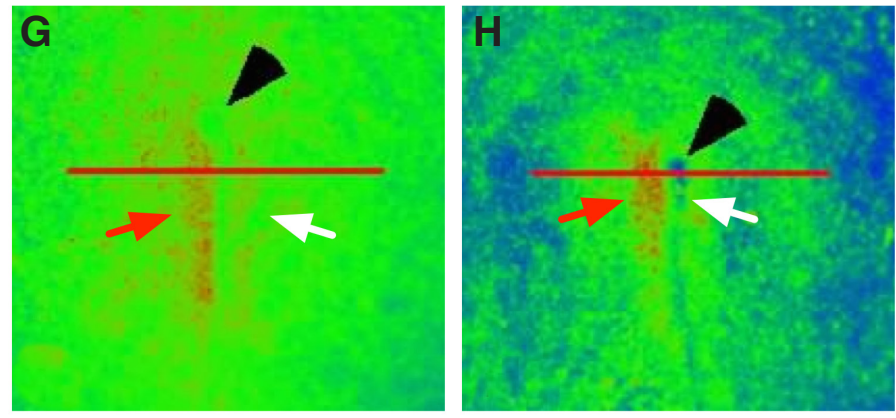
are independent compartments, each running its own side-specific gene-regulatory network. But is it possible that prior to that, the Land R sides actually need to communicate to decide their identities, before turning on appropriate asymmetric genes? The flat architecture of the chick blastoderm, together with its amenability to explant culture, allowed testing of this hypothesis (Levin and Mercola, 1999). It was found that when the early-streak embryo is cultured with the right lateral portion of the blastoderm removed, the left side failed turn on Nodal in a significant number of the animals. Even more strikingly (proving that this was not simply a damaged embryo that failed to turn on genes appropriately), the right side - which normally does not express the left-side marker Nodal, would often express Nodal robustly if the left tissue was removed. Importantly, the removed tissue was quite lateral, well away from the primitive streak, ruling out interference with the midline as a possible cause. It was thus found that the $L$ and $R$ sides do not know their identity a priori, but rely on each other's presence to decide L/R identity. How?

\section{Gap junctions - electrical synapses that mediate long-range LR coordination}

How might the $L$ and $R$ side tissues communicate across the whole blastoderm? One way for cross-tissue communication is through paths of cells connected by gap junctions (GJs) - electrical synapses directly connecting cells' interiors via an aqueous pore that is permeable to small molecules (Mathews and Levin, 2017). Work in the frog model showed that gap junctional paths around the early cleavage embryo were essential for normal laterality; the data supported a circumferential model whereby connectivity all along the dorsal side of a 32-cell embryo, and isolation across the ventral midline, were both required for normal asymmetry (Levin and Mercola, 1998). Despite the fact that the chick embryo at the relevant stages had a much different architecture than the frog, and tens of thousands of cells instead of 32, experiments suggested a similar topology. Connexin43, a gap junction protein, was found to be expressed throughout the blastoderm at the early streak stage, except in the primitive streak, as predicted by the model of circumferential connectivity around a region whose $L$ and $R$ sides are physiologically distinct (the significance of the consistently asymmetric expression of Cx43 in the much later Hensen's node remains unknown). Antisense oligonucleotides targeting Cx43 revealed that it was required for the correct sidedness of expression of Sonic hedgehog (Levin and Mercola, 1999), placing the gap junction-mediated signals upstream of the early asymmetric gene cascade. Thus, the chick embryo appeared to be using precisely the same "circumferential pattern around a midline zone of isolation" geometry as was found in frog, although projected onto a much different embryonic bodyplan. In this paradigm, the LR identity originates outside of Hensen's node, and instructs it laterally; this was confirmed by a number of elegant transplantation experiments (Pagan-Westphal and Tabin, 1998, Psychoyos and Stern, 1996, Yuan and Schoenwolf, 1998).

\section{Ion channels and neurotransmitters: propagating $L R$ information}

The embryo appears to require a circumferential path of physiologically-coupled cells upstream of the asymmetric gene cascade. Why? One hypothesis was that some small molecule signal(s) had to be shuttled from one side of the embryo to the other, enriching it in a spatial gradient as a kind of LR morphogen. Subsequent work addressed two questions: the nature of at least one left-right morphogen, and the transport mechanism.

A circumferential path of electrical connectivity around a zone of isolation is highly reminiscent of a simple circuit consisting of a conductor around a battery: a voltage gradient across the zone of isolation would exert an electrophoretic force across the gap junctionally-coupled ectoderm, forcing the unidirectional movement of specific charged molecules that could penetrate selective gap junctions. This simple model (which was motivated by prior work in developmental bioelectricity showing transport of biological molecules by endogenous electric fields (Poo, 1981, Woodruff and Telfer, 1980)) was tested simultaneously in chick and frog (Levin et al., 2002). Several ion translocators were found to be specifically expressed in the zone of junctional isolation (in the chick streak); these included the V-ATPase proton pump, the $\mathrm{H}, \mathrm{K}-\mathrm{ATP}$ ase proton/potassium exchanger, and two $\mathrm{K}^{+}$channels (Kir6.1 and Kir4.1) (Adams et al., 2006, Aw et al., 2008, Aw et al., 2010, Gros et al., 2009, Levin et al., 2002). The chick model enabled the first example of moleculardevelopmental bioelectricity work, as the use of a voltage-sensitive fluorescent dye revealed an endogenous bioelectric gradient, with the left side of the streak showing an $\mathrm{H}, \mathrm{K}-\mathrm{ATP}$ ase-dependent depolarization of resting potentials. While the chick had been a popular model for classical bioelectric work using electrodes, implicating endogenous ionic signaling in dorso-ventral (Jaffe and Stern, 1979, Stern, 1982) and limb/intestinal (Hotary and Robinson, 1990, Hotary and Robinson, 1992) patterning, it was the context of left-right asymmetry in the chick that established the molecular approaches to developmental bioelectricity which did not rely on laborious electrophysiological measurements of individual cells but revealed at once the whole electric landscape of a patterning system. These early chick results kicked off a plethora of subsequent work in developmental bioelectricity (Levin, 2017, Ozkucur et al., 2010).

Having identified a likely source of motive force for net-unidirectional movement of charged molecules, the next question became the molecular identity of such signals. The ideal candidate would be small (to fit through GJs, it has to be $<1 \mathrm{kD}$ ), significantly charged (to respond to the electrophoretic force), and known to be able to penetrate through GJs and to signal intracellularly. A candidate approach, biased toward molecules with a well-developed pharmacology and genetics, suggested the neurotransmitter serotonin. Using the numerous known drug blockers, as well as misexpression of serotonin receptors and other machinery, in both frog and chick embryos, it was found that the serotonin transporter and serotonin receptors $\mathrm{R} 3, \mathrm{R} 4$, and an intracellular binding protein were crucial components of LR patterning upstream of Sonic hedgehog leftsided expression (Fukumoto et al., 2005a, Fukumoto et al., 2005b). These data are consistent with the electrophoretic model, and have been simulated computationally to provide a quantitative picture of events upstream of asymmetric gene expression (Esser et al., 2006, Zhang and Levin, 2009b), although it is entirely possible that additional small molecule morphogens remain to be identified.

Serotonin movement was subsequently shown in the frog embryo to be dependent upon the V-ATPase function (Adams et al., 2006), and collapsing the voltage gradient across the zone of isolation disrupted the whole process and led to LR randomization of asymmetric genes and organ situs. Follow-up work in Xenopus also identified the intracellular receptor (the transcription factor Mad3) and showed that it binds Histone Deacetylase 1 to repress 
the Nodal transcriptional element on the right side. In retrospect, the early work in the chick led to perhaps the densest, best-understood (at the molecular-biological and quantitative levels) example of developmental bioelectricity, in which early biophysical events drive a spatialized second-messenger cascade that controls a gene regulatory network upstream of axial organ patterning of a major body axis. Moreover, the early discoveries on serotonergic signaling in pre-neural contexts in the chick have now fanned out to spur discoveries far beyond left-right asymmetry (Rea et al., 2013, Vandenberg et al., 2014, Vandenberg et al., 2012), including the bioelectric induction of conversion to melanoma (Blackiston et al., 2015, Lobikin et al., 2015), craniofacial patterning (Sullivan and Levin, 2016), and control of innervation of transplants (Blackiston et al., 2015). Together, a picture emerges in which decisions about large-scale properties are made via the control of neurotransmitter movement by electric activity - precisely as in the brain; this simple observation, initially made in chick, has presaged much work in the field of bioelectricity that echoed the same theme of deep conservation (Bates, 2015, Levin, 2017).

\section{The origin of asymmetry: avian embryos and early biophysical events in LR patterning}

Despite the drawback that avian embryos are generally not available for study until the blastoderm stages (hiding initial cleavage stages inside the maternal organism), avian models have nevertheless given important clues even about the earliest steps of LR patterning: midline determination and symmetry breaking.

Symmetry can be broken at a local level by clock-wise vs. counter-clockwise or L-hand vs. R-hand microscopic structures. However, in order to convert this information into a sense of position along the LR axis (important for cells to know whether to drive, for example, left-specific depolarization and gene expression), the embryo must establish a midline. When does this first take place? Conventional belief for amniotes is that the primary axis arises at the events that determine the location of the primitive streak at one point on the radial circumference of the early blastoderm (Khaner and Eyal-Giladi, 1989). However, a set of papers in avian models such as chick and finch suggest that we may be missing an important piece of LR-relevant biology. The study of gynandromorphs (animals that are half male and half female, due to chromosomal aberrations) reveals remarkably precise division of these characteristics along the midplane of the animal (Fig. 6). This is true not only in birds (Agate et al., 2003, Clinton et al., 2011, Lillie, 1931, Peer and Motz, 2014, Zhao et

Fig. 6. Conservation of early left-right (LR) mechanisms across phyla. This schematic shows the major classes of mechanisms involved in left-right patterning, and the model species in which they have been shown to operate. Details and references to each are given in (Levin and Palmer, 2007, Vandenberg and Levin, 2009). The chick model has been instrumental in the discovery of several of these, most notably the asymmetric gene cascade and upstream physiological signals like ion flows and gap junctional communication. Despite the significant differences in bodyplan architecture across phyla, many $L R$ mechanisms are broadly conserved and utilized to pattern the left-right axis of the body. al., 2010), but many other species across a very broad range of taxa (reviewed in Aw and Levin, 2008; Ma, 2013). Even humans, in cases of hermaphroditism (Mittwoch, 2000, 2001, 2008) and other syndromes (Happle et al., 1995; Konig et al., 2000), reveal a precise midline demarcation that is not consistent with an origin in cells that are random with respect to the midline. Precise left/right differences in such traits suggest that the separation into $L$ and $R$ halves occurred extremely early, allowing events like chromosomal nondisjunction post-fertilization to affect all of the descendants of one blastomere that gave rise to an entire body half. It is thus possible that, while the primitive streak can be artificially initiated anywhere (Bachvarova et al., 1998, Shah et al., 1997), the endogenous events of development in amniotes establish the $L$ and $R$ sides as early as do species like frog, where the first cell division usually sets the embryonic midline and thus defines the LR axis (Klein, 1987, Marrari et al., 2004, Masho, 1990).

There is broad consensus, consistent with Brown and Wolpert's definitive and prescient analysis (Brown and Wolpert, 1990), that LR asymmetry is broken and oriented via biophysical events involving a chiral structure. There is however considerable controversy regarding the nature of that structure and the conservation of this set of mechanisms across body-plans. One model suggests extracellular cilia, operating during neurulation to set up an extracellular vortical flow (Basu and Brueckner, 2008, McGrath et al., 2003), as the origin of asymmetry. Another model, driven initially by studies in Xenopus, first by Yost (Yost, 1991) and then others (Levin et al., 2002, Lobikin et al., 2012, McDowell et al., 2016b, Qiu et al., 2005), suggests the origin of asymmetry within chiral structures of the intracellular cytoskeleton - an interaction of microtubule organizing centers and cortical actin. The relative merits of the two models are discussed in detail in (Vandenberg et al., 2013,

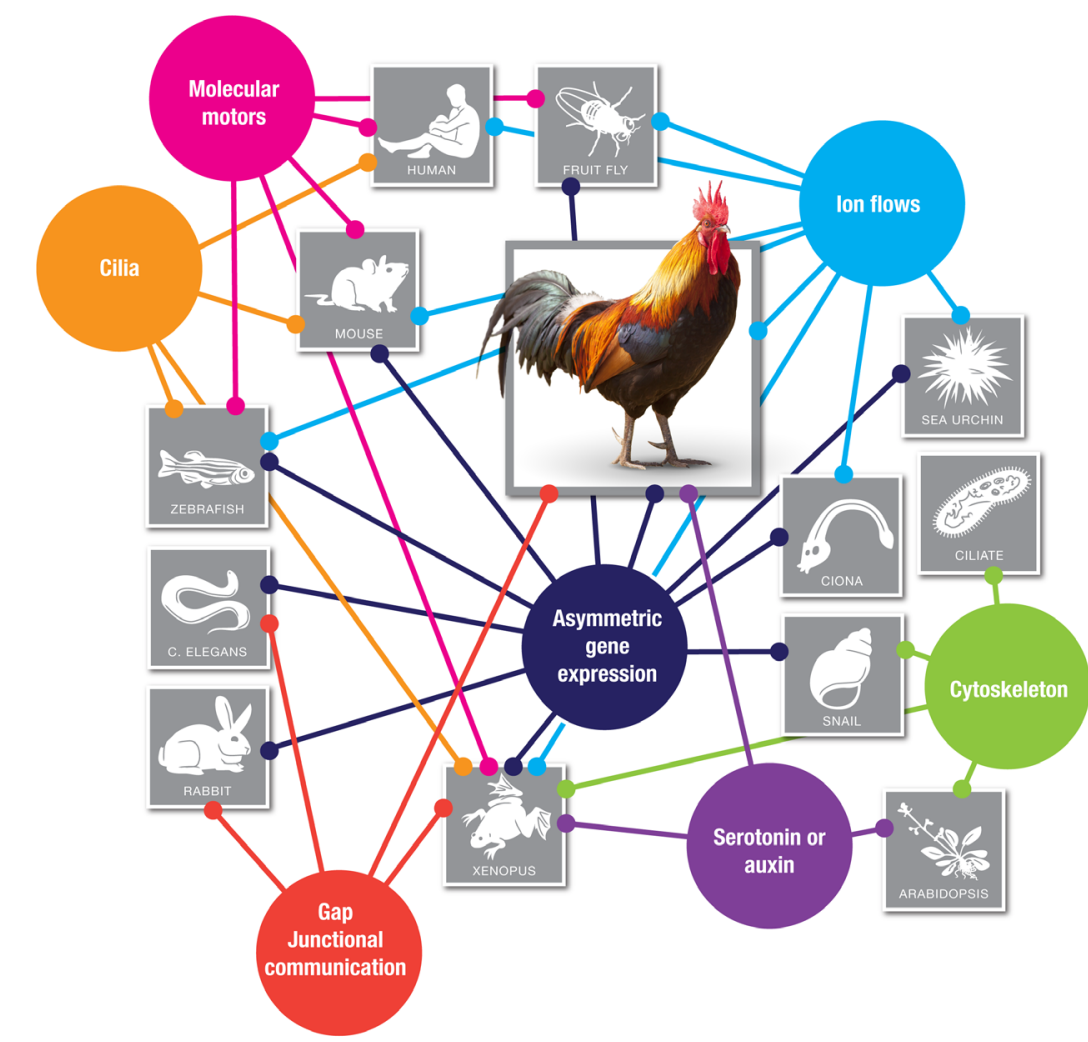


Vandenberg and Levin, 2009, Vandenberg and Levin, 2010b, Vandenberg and Levin, 2013). Because they utilize exactly the same molecular players (since almost all the same proteins function in ciliary motion as in intracellular transport), genetic experiments targeting these proteins, especially in mice where early stages are hard to analyze, usually do not distinguish between them. However, these two models make numerous different predictions (Vandenberg and Levin, 2013), and imply opposite conclusions about the evolutionary aspects of asymmetry. Because numerous phyla do not have cilia at the relevant stages but successfully establish asymmetry (Drosophila, C. elegans, Arabidopsis, etc.), the ciliary model is forced to suggest a highly divergent origin for asymmetry. Indeed, early studies suggested that this cannot even be conserved in amniotes, as the chick node does not have the required ciliated structure and hydrodynamic flow (Manner, 2001). More recent work showed that neither the chick (Bangs et al., 2011,
Manner, 2001) nor the pig (Gros et al., 2009) depend on cilia for their asymmetry. In contrast, other mechanisms operating in chick appear conserved to much more disparate model systems (Fig. 7 ), and new data are revealing conservation of ion translocators in mouse (Miyachi, 2017) and human patients (Fakhro et al., 2011), beyond the well-known examples in C. elegans, sea urchins, zebrafish, etc. (Vandenberg et al., 2013, Vandenberg and Levin, 2013).

From data in a range of model species, it is clear that numerous aspects of development, including maternal protein localization (Adams et al., 2006, Aw et al., 2008, Lobikin et al., 2012, Qiu et al., 2005), transcription (Vandenberg et al., 2014), Wnt signaling (Ohkawara and Niehrs, 2011), and localization of small signaling molecules (Onjiko et al., 2016) are already consistently asymmetric long before cilia appear even in animals that have them; most embryos can tell their Left from their Right at very early stages. Thus, the search for the origins of asymmetry has been extended
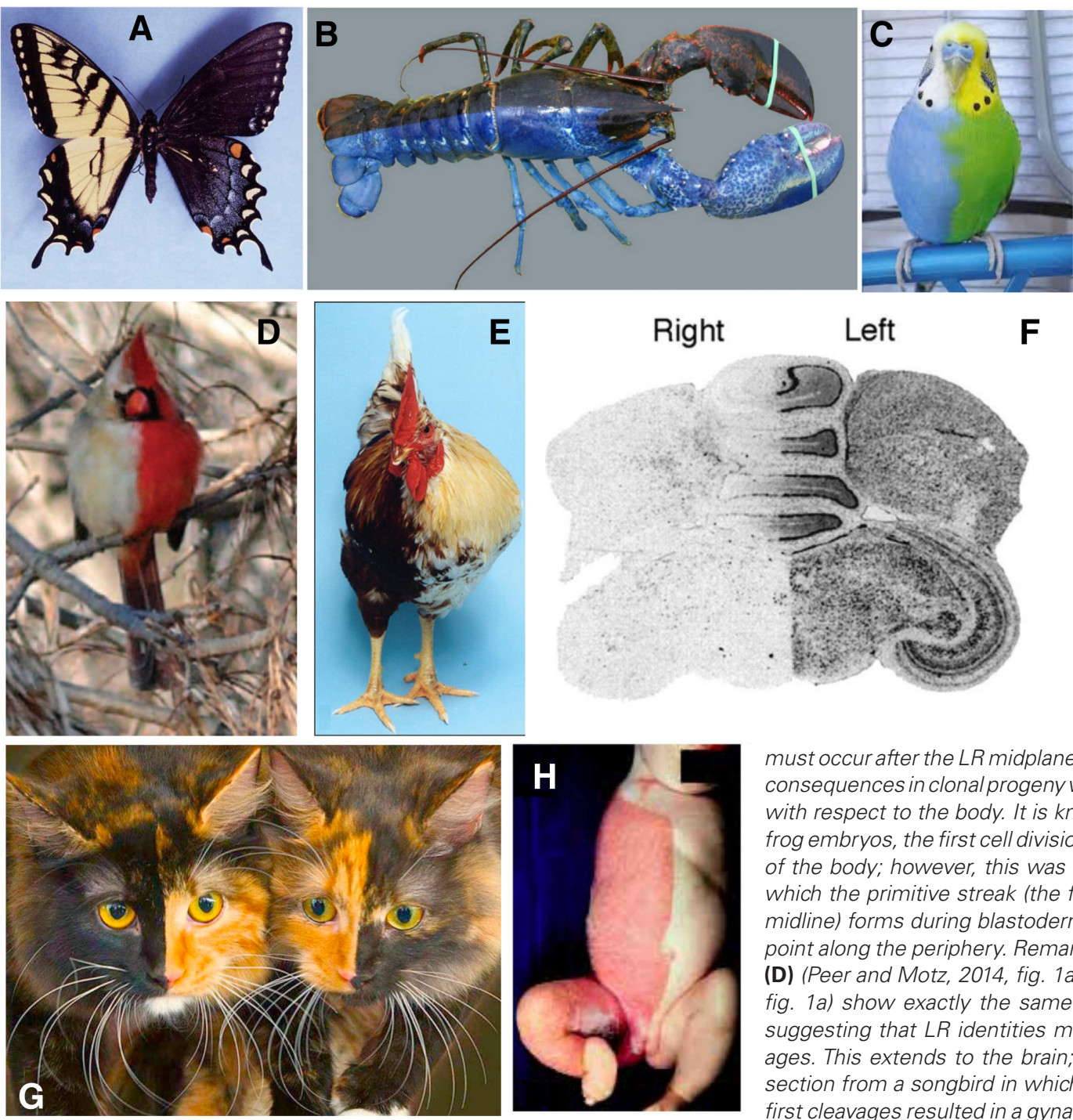

$\mathbf{F}$ must occur after the LR midplane has been established, otherwise their consequences in clonal progeny would be spread in random orientations with respect to the body. It is known that in many organisms, such as frog embryos, the first cell division usually establishes the $L$ and $R$ sides of the body; however, this was not thought to be true of amniotes in which the primitive streak (the first anatomical sign of an established midline) forms during blastoderm stages and could be initiated at any point along the periphery. Remarkably, bird gynandromorphs, cardinals (D) (Peer and Motz, 2014, fig. 1a) and roosters (E) (Clinton et al., 2011, fig. 1a) show exactly the same precisely-bilateral difference in cells, suggesting that $L R$ identities may be set as early the first few cleavages. This extends to the brain; (F) an in situ hybridization of a brain section from a songbird in which chromosomal aberrations during the first cleavages resulted in a gynandromorphy. The division between the female chromosome cells (dark signal) and the male chromosome cells

(no signal) is precisely down the anatomical midline of the brain, suggesting that the embryonic midline is determined long prior to streak development in bird in development. Taken from Fig. 6 of (Agate et al., 2003), copyright held by National Academy of Sciences. Even mammals, such as cats (G) and human embryos exhibiting CHILD syndrome (H) (Happle et al., 1995, Konig et al., 2000) show the same midline sharp demarcation, indicating that there is still much to be learned about the earliest events of development and their contributions to subsequent LR patterning. 
far upstream of neurulation (Oviedo and Levin, 2007, Trulioff et al., 2015); the chick is thus confirming a broad molecular conservation and not an outlier with respect to its non-reliance upon cilia. Thus, in this aspect, the chick model appears to be a much better conduit to understanding of amniote (and fundamental aspects of) asymmetry than mouse (Vandenberg, 2012), which has a very unique (cylinder-like) embryonic architecture. The embryonic chick offers a much more prototypical flat architecture and a conservation of early physiological events with a number of other species that suggest broad and deep principles by which evolution adapted the same components to impose asymmetry on radically different bodyplans.

\section{Conclusion}

\section{Overview}

The left-right $(\mathrm{L} / \mathrm{R})$ axis is defined as perpendicular to the two other main embryonic axes, anterior-posterior (A/P) and dorsalventral (D/V) axes. However, an intriguing feature of L/R asymmetry, is that there is no obvious reason why almost all normal individuals share the same left-to-right organization (situs solitus) rather than a population with equal proportion of situs solitus and inversus, since both are physiologically functional. The formation of $A / P$ and $\mathrm{D} / \mathrm{V}$ axes define an embryo with apparent bilateral symmetry. The lack of physical/visible difference between the left side and the right side of an embryo is a striking difference with A/P or D/V axes, which are set respective to well identified parameters such as the asymmetry of the oocyte or external cues (e.g. sperm entry point). This observation suggests the existence of an active and well-regulated developmental mechanism for breaking the apparent bilateral symmetry, rather than a pre-existing bias towards one side. Such a mechanism would initiate then amplify a subcellular-scale asymmetrical parameter, for example the chiral properties of actin (Danilchik et al., 2006), tubulin (Lobikin et al., 2012), or even DNA itself (Klar, 2008, Sauer and Klar, 2012).

\section{What we learned from the chick}

The chick embryo was instrumental in the discovery of the first molecular pathways establishing LR patterning: the asymmetric gene cascade during gastrulation. It has also facilitated the discovery of numerous other components, some still not wellunderstood, including tight junctions (Aw et al., 2010, Collins et al., 2015, Simard et al., 2005, Simard et al., 2006), asymmetric cell migration (Gros et al., 2009), programmed cell death (Kelly et al., 2002), and a set of bioelectric and neurotransmitter pathways upstream of the first known asymmetric genes (Fukumoto et al., 2005a, Fukumoto et al., 2005b, Levin et al., 2002). Its flat architecture makes it uniquely amenable to the study of physiological, genetic, and biomechanical aspects of asymmetry, from single cell movement to asymmetric organogenesis. Its limitation is the internal development at cleavage stages, but advances in culture methods and increasingly-available transgenic birds (Mozdziak and Petitte, 2004, Nishijima and lijima, 2013) continue to improve the usability of this classical model.

\section{Future prospects: a central place for avian models in the next frontiers of this field}

A number of aspects can be envisioned for the vibrant future of the chick model system in the field of LR asymmetry research.
Issues of midline determination (events at cleavage stages, or mechanisms by which the primitive streak can accurately bisect itself) are paramount. The LR patterning of embryos derived from repositioned and ectopic primitive streaks needs to be investigated, and a chick model of early twin:twin LR instruction, as has been studied in the frog (Vandenberg and Levin, 2010a, Vandenberg and Levin, 2012), would be highly informative for understanding the relationship between the mechanisms establishing the AP, DV, and LR axes. More topologies for twin orientation are possible in chick than frog (and especially easy in duck embryos, (Lutz, 1949)), suggesting numerous interesting experiments that exploit the blastoderm as an arena for exploring physiological and transcriptional signaling under different spatial orientations of circuit components including the zone of isolation, gap junctional field, and Hensen's node. A requirement for planar polarity has been identified in the chick (Zhang and Levin, 2009a), which is likely revealing a fundamental linkage between LR asymmetry and general mechanisms that propagate subcellular molecular information into order on the large scale in multiple tissues (Aw and Levin, 2009).

The asymmetric gene cascade most well-characterized in the chick has been identified in numerous other models - it is highly conserved, and shown by functional experiments to be instructive for LR positioning of the organs. Interestingly however, recent data in the frog model (McDowell et al., 2016a, McDowell et al., 2016b) revealed that in a given cohort of animals, induced errors in upstream asymmetric genes' expression patterns are progressively reduced over developmental time, not maintained or amplified as would be expected from a linear model where each sided gene fully determines the sidedness of downstream target genes. This instead suggests the existence of parallel, reparative mechanisms that can partially compensate and reduce errors even when key elements of the main LR pathway re perturbed. Testing this property in the chick embryo, which offers by far the richest set of interacting components is a clear next step. If confirmed within the wellstudied LR-GRN of the chick, this would significantly strengthen the role of LR patterning as not merely a self-contained aspect of development, but a prototypical example of living systems' robust regenerative capabilities. Likewise, important butpoorly-understood links between organ asymmetry and clinically-relevant phenomena such as cancer, immune system function, and CNS lateralization await deep investigation in the highly tractable avian embryonic models. Thus, as clearly revealed by its history, the chick model offers the creative scientist boundless opportunities for investigation into some of the most fascinating areas of interdisciplinary, multiscale biology of growth and form.

\footnotetext{
Acknowledgements

We thank the many members of the avian embryology and left-right asymmetry communities for their contributions over the years, and Christina Harrison for help editing the manuscript. M.L. gratefully acknowledges support of the Allen Discovery Center program through The Paul G. Allen Frontiers Group (12171) and of the G. Harold and Leila Y. Mathers Charitable Foundation (TFU141). A.H.M.B thanks support from Agence Nationale pour la Recherche (ANR Programme Blanc CrestNetMetabo), and Fondation pour la Recherche Médicale (FRM DEQ20150331733). M.L. is especially grateful to C. D. Stern, for personal mentoring in the techniques of chick embryology in 1993 that were instrumental in enabling the subsequent discovery of the asymmetric gene cascade. This paper is dedicated to early workers in this field, like P. Gray who in 1942 already studied the role of molecular chirality in directing asymmetry of avian development.
} 


\section{References}

ADAMS, D.S., ROBIUSANSON, K.R., FUKUMOTO, T., YUAN, S., ALBERTSON, R.C., YELICK, P., KUO, L., MCSWEENEY, M. and LEVIN, M. (2006). Early, H+V-ATPase-dependent proton flux is necessary for consistent left-right patterning of non-mammalian vertebrates. Development 133: 1657-1671.

AGATE, R.J., GRISHAM, W., WADE, J., MANN, S., WINGFIELD, J., SCHANEN, C., PALOTIE, A. and ARNOLD, A.P. (2003). Neural, not gonadal, origin of brain sex differences in a gynandromorphic finch. Proc Natl Acad Sci USA 100: 4873-8.

AIRD, I. (1959). Conjoined twins. British Medical Journal 1: 1313-1315.

AW, S., ADAMS, D.S., QIU, D. and LEVIN, M. (2008). H,K-ATPase protein localization and Kir4. 1 function reveal concordance of three axes during early determination of left-right asymmetry. Mech Dev 125: 353-372.

AW, S., KOSTER, J., PEARSON, W., NICHOLS, C., SHI, N.Q., CARNEIRO, K. and LEVIN, M. (2010). The ATP-sensitive K(+)-channel (K(ATP)) controls early left-right patterning in Xenopus and chick embryos. Dev Biol 346: 39-53.

AW, S. and LEVIN, M. (2008). What's left in asymmetry? Dev Dyn 237: 3453-3463.

AW, S. and LEVIN, M. (2009). Is left-right asymmetry a form of planar cell polarity? Development 136: 355-366.

BACHVAROVA, R.F., SKROMNE, I. and STERN, C.D. (1998). Induction of primitive streak and Hensen's node by the posterior marginal zone in the early chick embryo. Development 125: 3521-3534.

BANGS, F., ANTONIO, N., THONGNUEK, P., WELTEN, M., DAVEY, M.G., BRISCOE, J. and TICKLE, C. (2011). Generation of mice with functional inactivation of talpid3, a gene first identified in chicken. Development 138: 3261-3272.

BASU, B. and BRUECKNER, M. (2008). Cilia: multifunctional organelles at the center of vertebrate left-right asymmetry. Curr Top Dev Biol 85: 151-174.

BATES, E. (2015). Ion Channels in Development and Cancer. Annu Rev Cell Dev Biol 31: 231-247.

BLACKISTON, D.J., ANDERSON, G.M., RAHMAN, N., BIECK, C. and LEVIN, M. (2015). A novel method for inducing nerve growth via modulation of host resting potential: gap junction-mediated and serotonergic signaling mechanisms. Neurotherapeutics 12: 170-184.

BOETTGER, T., WITTLER, L. and KESSEL, M. (1999). FGF8 functions in the specification of the right body side of the chick. Curr Biol 9: 277-280.

BRANFORD, W.W., ESSNER, J.J. and YOST, H.J. (2000). Regulation of gut and heart left-right asymmetry by context-dependent interactions between Xenopus lefty and BMP4 signaling. Dev. Biol. 223: 291-306.

BROWN, N.A. and WOLPERT, L. (1990). The development of handedness in left/ right asymmetry. Development 109: 1-9.

CASEY, B. (1998). Two rights make a wrong: human left-right malformations. Human Mol. Genet. 7: 1565-1571.

CATANA, A. and APOSTU, A.P. (2017). The determination factors of left-right asymmetry disorders- a short review. Clujul Med 90: 139-146.

CHEN, T.H., HSU, J.J., ZHAO, X., GUO, C., WONG, M.N., HUANG, Y., LI, Z., GARFINKEL, A., HO, C.M., TINTUT, Y. et al., (2012). Left-Right Symmetry Breaking in Tissue Morphogenesis via Cytoskeletal Mechanics. Circulation Res. 110:551-559.

CHIB, P., GROVER, D.N. and SHAHI, B.N. (1977). Unusual occurrence of dextrocardia with situs inversus in succeeding generations of a family. J Med Genet 14: 30-2.

CLINTON, M., ZHAO, D., NANDI, S. and MCBRIDE, D. (2011). Evidence for avian cell autonomous sex identity (CASI) and implications for the sex-determination process? Chromosome Res. 20: 177-90.

COCKAYNE, E. (1938). The genetics of transposition of the viscera. Quart. J. Med. 31: 479-493.

COLLINS, M.M., BAUMHOLTZ, A.I., SIMARD, A., GREGORY, M., CYR, D.G. and RYAN, A.K. (2015). Claudin-10 is required for relay of left-right patterning cues from Hensen's node to the lateral plate mesoderm. Dev Biol 401: 236-248.

COOKE, J. (1995). Vertebrate embryo handedness. Nature 374: 681.

CORCOS, A.P., TZIVONI, D. and MEDINA, A. (1989). Long QT syndrome and complete situs inversus. Preliminary report of a family. Cardiology 76: 228-33.

CUNIFF, C., JONES, K., JONES, M., SAUNDERS, B., SHEPARD, T. and BENIRSCHKE, K. (1988). Laterality defects in conjoined twins: implications for normal asymmetry in human embryogenesis. Am. J. Med. Genet. 31: 669-677.

DANE, S., ERDEM, T. and GUMUSTEKIN, K. (2001). Cell-mediated immune hyper- sensitivity is stronger in the left side of the body than the right in healthy young subjects. Percept Mot Skills 93: 329-332.

DANILCHIK, M.V., BROWN, E.E. and RIEGERT, K. (2006). Intrinsic chiral properties of the Xenopus egg cortex: an early indicator of left-right asymmetry? Development 133: 4517-4526.

DATHE, V., GAMEL, A., MANNER, J., BRAND-SABERI, B. and CHRIST, B. (2002). Morphological left-right asymmetry of Hensen's node precedes the asymmetric expression of Shh and Fgf8 in the chick embryo. Anat. Embryol. 205: 343-354.

DAVIS, N.M., KURPIOS, N.A., SUN, X., GROS, J., MARTIN, J.F. and TABIN, C.J. (2008). The chirality of gut rotation derives from left-right asymmetric changes in the architecture of the dorsal mesentery. Dev Cell 15: 134-145.

DELANEY, M. and BOYD, T.K. (2007). Case report of unilateral clefting: is sonic hedgehog to blame? Pediatr Dev Pathol 10: 117-120.

DIMONTE, A., ADAMATZKY, A., EROKHIN, V. and LEVIN, M. (2016). On chirality of slime mould. Biosystems 140: 23-27.

DUBOC, V., DUFOURCQ, P., BLADER, P. and ROUSSIGNE, M. (2015). Asymmetry of the Brain: Development and Implications. Ann. Rev. Genetics 49: 647-672.

ESSER, A.T., SMITH, K.C., WEAVER, J.C. and LEVIN, M. (2006). Mathematical model of morphogen electrophoresis through gap junctions. Dev Dyn 235: 2144-2159.

FAKHRO, K.A., CHOI, M., WARE, S.M., BELMONT, J.W., TOWBIN, J.A., LIFTON, R.P., KHOKHA, M.K. and BRUECKNER, M. (2011). Rare copy number variations in congenital heart disease patients identify unique genes in left-right patterning. Proc. Natl. Acad. Sci. USA108: 2915-2920.

FREEMAN, G. and LUNDELIUS, J. (1982). The developmental genetics of dextrality and sinistrality in the gastropod Lymnaea peregra. Wilhelm Roux's Archives 191: 69-83.

FRETZAYAS, A. and MOUSTAKI, M. (2016). Clinical spectrum of primary ciliary dyskinesia in childhood. World J Clin Pediatr 5: 57-62.

FUJINAGA, M. and BADEN, J.M. (1991a). Critical period of rat development when sidedness of asymmetric body structures is determined. Teratology 44: 453-462.

FUJINAGA, M. and BADEN, J.M. (1991b). Evidence for an adrenergic mechanism in the control of body asymmetry. Dev Biol 143: 203-205.

FUJINAGA, M., BADEN, J.M., SHEPARD, T.H. and MAZZE, R.I. (1990). Nitrous oxide alters body laterality in rats. Teratology 41: 131-135.

FUKUMOTO, T., BLAKELY, R. and LEVIN, M. (2005a). Serotonin transporter function is an early step in left-right patterning in chick and frog embryos. Dev Neurosci 27: 349-363.

FUKUMOTO, T., KEMA, I.P. and LEVIN, M. (2005b). Serotonin signaling is a very early step in patterning of the left-right axis in chick and frog embryos. Curr Biol 15: 794-803

GARCIA-CASTRO, M.I., VIELMETTER, E. and BRONNER-FRASER, M. (2000) $\mathrm{N}-$-Cadherin, a cell adhesion molecule involved in establishment of embryonic left-right asymmetry. Science 288: 1047-1051.

GILBERT, S.F. (2006). Developmental Biology. Sinauer Associates, Massachusetts.

GOLBIN, A., GOLBIN, Y., KEITH, L. and KEITH, D. (1993). Mirror imaging in twins: biological polarization. Acta Geneticae Medicae et Gemellologiae 42: 237-243.

GROS, J., FEISTEL, K., VIEBAHN, C., BLUM, M. and TABIN, C.J. (2009). Cell movements at Hensen's node establish left/right asymmetric gene expression in the chick. Science 324: 941-944.

HAMBURGER, V. and HAMILTON, H.L. (1951). A series of normal stages in the development of the chick embryo. J. Morphol. 88: 49-92.

HAPPLE, R., MITTAG, H. and KUSTER, W. (1995). The CHILD nevus: a distinct skin disorder. Dermatology 191: 210-216.

HASHIMOTO, T. (2002). Molecular genetic analysis of left-right handedness in plants. Philos Trans R Soc Lond B Biol Sci 357: 799-808.

HOSHINO, A., KOIDE, M., ONO, T. and YASUGI, S. (2005). Sex-specific and left-right asymmetric expression pattern of Bmp7 in the gonad of normal and sex-reversed chicken embryos. Dev Growth Differ 47: 65-74.

HOTARY, K.B. and ROBINSON, K.R. (1990). Endogenous electrical currents and the resultant voltage gradients in the chick embryo. Dev Biol 140: 149-160.

HOTARY, K.B. and ROBINSON, K.R. (1992). Evidence of a role for endogenous electrical fields in chick embryo development. Development 114: 985-996.

HOYLE, C., BROWN, N.A. and WOLPERT, L. (1992). Development of left/right handedness in the chick heart. Development 115: 1071-1078. 
HUMMEL, K.P. and CHAPMAN, D.B. (1959). Visceral inversion and associated anomalies in the mouse. J. Heredity 50: 9-23.

ISAAC, A., SARGENT, M.S. and COOKE, J. (1997). Control of vertebrate left-right asymmetry by a snail-related zinc finger gene. Science 275: 1301.

ISHIMARU, Y., KOMATSU, T., KASAHARA, M., KATOH-FUKUI, Y., OGAWA, H., TOYAMA, Y., MAEKAWA, M., TOSHIMORI, K., CHANDRARATNA, R.A., MOROHASHI, K. et al., (2008). Mechanism of asymmetric ovarian development in chick embryos. Development 135: 677-85.

JAFFE, L.F. and STERN, C.D. (1979). Strong electrical currents leave the primitive streak of chick embryos. Science 206: 569-71.

KELLY, K.A., WEI, Y. and MIKAWA, T. (2002). Cell death along the embryo midline regulates left-right sidedness. Dev Dyn 224: 238-44.

KENNEDY, D., O'CRAVEN, K., TICHO, B., GOLDSTEIN, A., MAKRIS, N. and HENSON, J. (1999). Structural and functional brain asymmetries in human situs inversus totalis. Neurology 53: 1260-1265.

KENNEDY, M.P., OMRAN, H., LEIGH, M.W., DELL, S., MORGAN, L., MOLINA, P.L., ROBINSON, B.V., MINNIX, S.L., OLBRICH, H., SEVERIN, T. et al., (2007). Congenital heart disease and other heterotaxic defects in a large cohort of patients with primary ciliary dyskinesia. Circulation 115: 2814-2821.

KHANER, O. and EYAL-GILADI, H. (1989). The chick's marginal zone and primitive streak formation. Dev. Biol. 134: 206-214.

KLAR, A.J. (2003). Human handedness and scalp hair-whorl direction develop from a common genetic mechanism. Genetics 165: 269-276.

KLAR, A.J. (2008). Support for the selective chromatid segregation hypothesis advanced for the mechanism of left-right body axis development in mice. Breast Dis 29: 47-56.

KLEIN, S.L. (1987). The first cleavage furrow demarcates the dorsal-ventral axis in Xenopus embryos. Dev. Biol. 120: 299-304.

KONIG, A., HAPPLE, R., BORNHOLDT, D., ENGEL, H. and GRZESCHIK, K.H. (2000). Mutations in the NSDHL gene, encoding a 3beta-hydroxysteroid dehydrogenase, cause CHILD syndrome. Am. J. Med. Genet. 90: 339-46.

KOSAKI, K. and CASEY, B. (1998). Genetics of human left-right axis malformations. Sem. Cell Dev. Biol. 9: 89-99.

KURPIOS, N.A., IBANES, M., DAVIS, N.M., LUI, W., KATZ, T., MARTIN, J.F., BELMONTE, J.C. and TABIN, C.J. (2008). The direction of gut looping is established by changes in the extracellular matrix and in cell:cell adhesion. Proc Natl Acad Sci USA 105: 8499-8506.

LATACHA, K.S., REMOND, M.C., RAMASUBRAMANIAN, A., CHEN, A.Y., ELSON, E.L. and TABER, L.A. (2005). Role of actin polymerization in bending of the early heart tube. Dev Dyn 233: 1272-1286.

LEVIN, M. (1997). Left-right asymmetry in vertebrate embryogenesis. Bioessays 19: 287-296.

LEVIN, M., JOHNSON, R.L., STERN, C.D., KUEHN, M. and TABIN, C. (1995). A molecular pathway determining left-right asymmetry in chick embryogenesis. Cell 82: 803-814.

LEVIN, M. and MERCOLA, M. (1998). Gap junctions are involved in the early generation of left-right asymmetry. Dev Biol 203: 90-105.

LEVIN, M. and MERCOLA, M. (1999). Gap junction-mediated transfer of left-right patterning signals in the early chick blastoderm is upstream of Shh asymmetry in the node. Development 126: 4703-4714.

LEVIN, M. and NASCONE, N. (1997). Two molecular models of initial left-right asymmetry generation. Med Hypotheses 49: 429-435.

LEVIN, M., PAGAN, S., ROBERTS, D.J., COOKE, J., KUEHN, M.R. and TABIN, C.J. (1997). Left/right patterning signals and the independent regulation of different aspects of Situs in the chick embryo. Dev. Biol. 189: 57-67.

LEVIN, M. and PALMER, A.R. (2007). Left-right patterning from the inside out: widespread evidence for intracellular control. Bioessays 29: 271-287.

LEVIN, M., PEZZULO, G., AND FINKELSTEIN, J. M. (2017). Endogenous Bioelectric Signaling Networks: Exploiting Voltage Gradients for Control of Growth and Form. Ann. Rev. Biomed. Engin. 19: 353-387.

LEVIN, M., ROBERTS, D.J., HOLMES, L.B. and TABIN, C. (1996). Laterality defects in conjoined twins. Nature 384: 321.

LEVIN, M., THORLIN, T., ROBINSON, K.R., NOGI, T. and MERCOLA, M. (2002). Asymmetries in $\mathrm{H}+/ \mathrm{K}+-\mathrm{ATP}$ ase and cell membrane potentials comprise a very early step in left-right patterning. Cell 111: 77-89.
LILLIE, F.R. (1931). Bilateral Gynandromorphism and Lateral Hemihypertrophy in Birds. Science 74: 387-390.

LINASK, K.K., HAN, M.D., LINASK, K.L., SCHLANGE, T. and BRAND, T. (2003). Effects of antisense misexpression of CFC on downstream flectin protein expression during heart looping. Dev Dyn 228: 217-230.

LINASK, K.K., YU, X., CHEN, Y. and HAN, M.D. (2002). Directionality of heart looping: effects of Pitx2c misexpression on flectin asymmetry and midline structures. Dev Biol 246: 407-417.

LOBIKIN, M., LOBO, D., BLACKISTON, D.J., MARTYNIUK, C.J., TKACHENKO, E. and LEVIN, M. (2015). Serotonergic regulation of melanocyte conversion: A bioelectrically regulated network for stochastic all-or-none hyperpigmentation. Sci Signal 8: ra99.

LOBIKIN, M., WANG, G., XU, J., HSIEH, Y.W., CHUANG, C.F., LEMIRE, J.M. and LEVIN, M. (2012). Early, nonciliary role for microtubule proteins in left-right patterning is conserved across kingdoms. Proc. Natl. Acad. Sci. USA. 109: 12586-12591.

LUTZ, H. (1949). Sur la production experimentale de la polyembryonie et de la monstruosite double chez les oiseaux. Archs Anat. Microsc. Morph. Exp. 38: 79-144.

MA, K. (2013). Embryonic left-right separation mechanism allows confinement of mutation-induced phenotypes to one lateral body half of bilaterians. Am. J. Med. Genet. 161: 3095-3114.

MANGOLD, O. (1921). Situs inversus bei Triton. Arch. Entwickl.-Mech. Org. 48:505-516.

MANNER, J. (2001). Does an equivalent of the "ventral node" exist in chick embryos? A scanning electron microscopic study. Anat. Embryol. 203: 481-90.

MANNER, J. (2004). On rotation, torsion, lateralization, and handedness of the embryonic heart loop: New insights from a simulation model for the heart loop of chick embryos. Anat Rec 278A: 481-492.

MARRARI, Y., ROUVIERE, C. and HOULISTON, E. (2004). Complementary roles for dynein and kinesins in the Xenopus egg cortical rotation. Dev Biol 271: 38-48.

MASHO, R. (1990). Close Correlation between the 1st Cleavage Plane and the Body Axis in Early Xenopus Embryos. Dev. Growth Differen. 32: 57-64.

MATHEWS, J. and LEVIN, M. (2017). Gap junctional signaling in pattern regulation: Physiological network connectivity instructs growth and form. Dev Neurobiol 77: 643-673.

MCCAIN, E. and MCCLAY, D. (1994). The establishment of bilateral asymmetry in sea urchin embryos. Development 120: 395-404.

MCDOWELL, G., RAJADURAI, S. and LEVIN, M. (2016a). From cytoskeletal dynamics to organ asymmetry: a nonlinear, regulative pathway underlies left-right patterning. Philos Trans R Soc Lond B Biol Sci 371: 20150409.

MCDOWELL, G.S., LEMIRE, J.M., PARE, J.F., CAMMARATA, G., LOWERY, L.A. and LEVIN, M. (2016b). Conserved roles for cytoskeletal components in determining laterality. Integr. Biol. 8: 267-286.

MCGRATH, J., SOMLO, S., MAKOVA, S., TIAN, X. and BRUECKNER, M. (2003). Two populations of node monocilia initiate left-right asymmetry in the mouse. Cell 114: 61-73.

MEADOR, K.J., LORING, D.W., RAY, P.G., HELMAN, S.W., VAZQUEZ, B.R. and NEVEU, P.J. (2004). Role of cerebral lateralization in control of immune processes in humans. Ann Neurol 55: 840-4.

MENDELSON, N.H. and KEENER, S.L. (1982). Clockwise and counterclockwise pinwheel colony morphologies of Bacillus subtilis are correlated with the helix hand of the strain. J. Bacteriol. 151: 455-7.

MENO, C., TAKEUCHI, J., SAKUMA, R., KOSHIBA-TAKEUCHI, K., OHISHI, S., SAIJOH, Y., MIYAZAKI, J., TEN DIJKE, P., OGURA, T. and HAMADA, H. (2001). Diffusion of nodal signaling activity in the absence of the feedback inhibitor Lefty2. Dev Cell 1: 127-138.

MITAL, O.P., PRASAD, R. and RAO, M.S. (1974). Situs inversus (totalis) among two brothers: a case report. Indian J Chest Dis 16: 188-190.

MITCHISON, H.M., SCHMIDTS, M., LOGES, N.T., FRESHOUR, J., DRITSOULA, A., HIRST, R.A., O'CALLAGHAN, C., BLAU, H., AL DABBAGH, M., OLBRICH, $\mathrm{H}$. et al., (2012). Mutations in axonemal dynein assembly factor DNAAF3 cause primary ciliary dyskinesia. Nat Genet 44: 381-389, S1-S2.

MITTWOCH, U. (2000). Genetics of sex determination: exceptions that prove the rule. Molec. Genet. Metabol. 71: 405-10.

MITTWOCH, U. (2001). Genetics of mammalian sex determination: some unloved exceptions. J Exp Zool 290: 484-9.

MITTWOCH, U. (2008). Different gene expressions on the left and the right: a 
genotype/phenotype mismatch in need of attention. Ann. Human Genet. 72: 2-9.

MIYACHI, Y. (2017). H+/K+-ATPase-Inhibition Causes Left-RightAortic Arch Inversion in Mouse Development. Reprod. Sci. 1933719116687654

MONSORO-BURQ, A. and LE DOUARIN, N. (2000). Left-right asymmetry in BMP4 signalling pathway during chick gastrulation. Mech Dev 97: 105-108.

MONSORO-BURQ, A. and LE DOUARIN, N.M. (2001). BMP4 plays a key role in left-right patterning in chick embryos by maintaining Sonic Hedgehog asymmetry. Molec. Cell 7: 789-799.

MORRILL, C.V. (1919). Symmetry reversal and mirror imaging in monstrous trout and a comparison with similar conditions in human double monsters. Anatomical Rec. 16: 265-292.

MOZDZIAK, P.E. and PETITTE, J.N. (2004). Status of transgenic chicken models for developmental biology. Dev Dyn 229: 414-421.

MURRAY, J. and CLARKE, B. (1966). The inheritance of polymorphic shell characters in Partula (Gastropoda). Genetics 54: 1261-1277.

NEVILLE, A. (1976). Animal Asymmetry. Edward Arnold, London.

NEWMAN, H. (1916). Heredity and organic symmetry in armadillo quadruplets. Biol. Bull. 29: 1-32.

NISHIJIMA, K. and IIJIMA, S. (2013). Transgenic chickens. Dev Growth Differ 55: 207-216.

OHKAWARA, B. and NIEHRS, C. (2011). An ATF2-based luciferase reporter to monitor non-canonical Wnt signaling in Xenopus embryos. Dev Dyn 240: 188-194.

OHUCHI, H., KIMURA, S., WATAMOTO, M. and ITOH, N. (2000). Involvement of fibroblast growth factor (FGF) 18-FGF8 signaling in specification of left-right asymmetry and brain and limb development of the chick embryo. Mech. Dev. 95:55-66.

ONJIKO, R.M., MORRIS, S.E., MOODY, S.A. and NEMES, P. (2016). Single-cell mass spectrometry with multi-solvent extraction identifies metabolic differences between left and right blastomeres in the 8-cell frog (Xenopus) embryo. Analyst. 141: 3648-3656.

OVIEDO, N.J. and LEVIN, M. (2007). Gap junctions provide new links in left-right patterning. Cell 129: 645-647.

OZKUCUR, N., EPPERLEIN, H.H. and FUNK, R.H. (2010). lon imaging during axolotl tail regeneration in vivo. Dev Dyn 239: 2048-2057.

PAGAN-WESTPHAL, S.M. and TABIN, C.J. (1998). The transfer of left-right positional information during chick embryogenesis. Cell 93: 25-35.

PATEL, K., ISAAC, A. and COOKE, J. (1999). Nodal signalling and the roles of the transcription factors SnR and Pitx2 in vertebrate left-right asymmetry. Curr Biol 9: 609-612.

PAULOZZI, L.J. and LARY, J.M. (1999). Laterality patterns in infants with external birth defects. Teratology 60: 265-271.

PEER, B.D. and MOTZ, R.W. (2014). Observations of a Bilateral Gynandromorph Northern Cardinal (Cardinalis cardinalis). Wilson J. Ornithol. 126: 778-781.

PEETERS, H. and DEVRIENDT, K. (2006). Human laterality disorders. Eur J Med Genet 49: 349-362.

POO, M. (1981). In situelectrophoresis of membrane components. Annu Rev Biophys Bioeng 10: 245-276.

PSYCHOYOS, D. and STERN, C. (1996). Restoration of the organizer after radical ablation of Hensen's node and the anterior primitive streak in the chick embryo. Development 122: 3263-3273.

QIU, D., CHENG, S.M., WOZNIAK, L., MCSWEENEY, M., PERRONE, E. and LEVIN, M. (2005). Localization and loss-of-function implicates ciliary proteins in early, cytoplasmic roles in left-right asymmetry. Dev Dyn 234: 176-189.

RAMSDELL, A.F. (2005). Left-right asymmetry and congenital cardiac defects: getting to the heart of the matter in vertebrate left-right axis determination. Dev Biol288: 1-20.

REA, A.C., VANDENBERG, L.N., BALL, R.E., SNOUFFER, A.A., HUDSON, A.G., ZHU, Y., MCLAIN, D.E., JOHNSTON, L.L., LAUDERDALE, J.D., LEVIN, M. et al., (2013). Light-activated serotonin for exploring its action in biological systems. Chem. Biol. 20: 1536-1546.

ROBICHAUX, J.P., HALLETT, R.M., FUSELER, J.W., HASSELL, J.A. and RAMSDELL, A.F. (2015). Mammary glands exhibit molecular laterality and undergo left-right asymmetric ductal epithelial growth in MMTV-cNeu mice. Oncogene 34:2003-2010.

RODRIGUEZ ESTEBAN, C., CAPDEVILA, J., ECONOMIDES, A.N., PASCUAL, J., ORTIZ, A. and IZPISUA BELMONTE, J.C. (1999). The novel Cer-like protein Caronte mediates the establishment of embryonic left-right asymmetry. Nature
401: $243-51$

ROGERS, L.J. (2008). Development and function of lateralization in the avian brain Brain Res Bull 76: 235-244.

ROGERS, L.J., MUNRO, U., FREIRE, R., WILTSCHKO, R. and WILTSCHKO, W. (2008). Lateralized response of chicks to magnetic cues. Behav Brain Res 186: 66-71.

RYAN, A., BLUMBERG, B., RODRIGUEZ-ESTEBAN, C., YONEI-TAMURA, S. TAMURA, K., TSUKUI, T., PENA, J.D.L., SABBAGH, W., GREENWALD, J., CHOE, S. et al., (1998). Pitx2 determines left-right asymmetry of internal organs in vertebrates. Nature 394: 545-551.

SANDSON, T.A., WEN, P.Y. and LEMAY, M. (1992). Reversed cerebral asymmetry in women with breast cancer. Lancet 339: 523-524.

SAUER, S. and KLAR, A.J. (2012). Left-right symmetry breaking in mice by left-right dynein may occur via a biased chromatid segregation mechanism, without directly involving the Nodal gene. Front. Oncology 2: 166.

SCHREINER, C., SCOTT, W., SUPP, D. and POTTER, S. (1993). Correlation of forelimb malformation asymmetries with visceral organ situs in the transgenic mouse insertional mutation legless. Dev. Biol. 158: 560-562.

SCHWIND, J.L. (1934). Symmetry in spontaneous twinning in Rana sylvatica. Anatomical Rec. 58: 37-.

SHAH, S.B., SKROMNE, I., HUME, C.R., KESSLER, D.S., LEE, K.J., STERN, C.D. and DODD, J. (1997). Misexpression of chick Vg1 in the marginal zone induces primitive streak formation. Development 124: 5127-5138.

SHAMIM, H. and MASON, I. (1999). Expression of Fgf4 during early development of the chick embryo. Mech Dev 85: 189-92.

SIMARD, A., DI GIORGIO, L., AMEN, M., WESTWOOD, A., AMENDT, B.A. and RYAN, A.K. (2009). The Pitx2c N-terminal domain is a critical interaction domain required for asymmetric morphogenesis. Dev Dyn 238: 2459-2470.

SIMARD, A., DI PIETRO, E. and RYAN, A.K. (2005). Gene expression pattern of Claudin-1 during chick embryogenesis. Gene Expr Patterns 5: 553-560.

SIMARD, A., PIETRO, E.D., YOUNG, C.R., PLAZA, S. and RYAN, A.K. (2006). Alterations in heart looping induced by overexpression of the tight junction protein Claudin-1 are dependent on its C-terminal cytoplasmic tail. Mech Dev123:210-227.

SINGH, G., SUPP, D., SCHREINER, C., MCNEISH, J., MERKER, H., COPELAND, N., JENKINS, N., POTTER, S. and SCOTT, W. (1991). legless insertional mutation: morphological, molecular, and genetic characterization. Genes Dev. 5:2245-2255.

SMITH, A.T., SACK, G.H., JR. and TAYLOR, G.J. (1979). Holt-Oram syndrome. J Pediatr 95: 538-543.

SPEMANN, H. and FALKENBERG, H. (1919). Über Asymmetrische Entwicklung und Situs inversus viscerum bei Zwillingen und Doppelbildungen. Wilhelm Roux' Archives Entwicklungsmechanic Organismen 45: 371-422.

ST AMAND, T.R., RA, J., ZHANG, Y., HU, Y., BABER, S.I., QIU, M. and CHEN, Y. (1998). Cloning and expression pattern of chicken Pitx2: a new component in the $\mathrm{SHH}$ signaling pathway controlling embryonic heart looping. Biochem. Biophys. Res. Commun. 247: 100-105.

STALSBERG, H. (1969). The origin of heart asymmetry: right and left contributions to the early chick embryo heart. Dev. Biol. 19: 109-127.

STERN, C. (1982). Experimental reversal of polarity in chick embryo epiblast sheets in vitro. Exp. Cell Res. 140: 468-471

SULLIVAN, K.G. and LEVIN, M. (2016). Neurotransmitter signaling pathways required for normal development in Xenopus laevis embryos: a pharmacological survey screen. J Anat 229: 483-502.

TORGERSEN, J. (1950). Situs inversus, asymmetry and twinning. Am. J. Hum Genet. 2: 361-370.

TRULIOFF, A.S., MALASHICHEV, Y.B. and ERMAKOV, A.S. (2015). Artificial inversion of the left-right visceral asymmetry in vertebrates: Conceptual approaches and experimental solutions. Russian J. Dev. Biol. 46: 307-325.

TSUDA, T., PHILP, N., ZILE, M.H. and LINASK, K.K. (1996). Left-right asymmetric localization of flectin in the extracellular matrix during heart looping. Dev Biol 173: 39-50.

TUINSTRA, E., DEJONG, G. and SCHARLOO, W. (1990). Lack of response to family selection for directional asymmetry in Drosophila melanogaster. Proc. Royal Soc. London, Series B 241: 146-152.

VALLORTIGARA, G., COZZUTTI, C., TOMMASI, L. and ROGERS, L.J. (2001). How birds use their eyes: Opposite left-right specialization for the lateral and frontal 
visual hemifield in the domestic chick. Curr. Biol.11: 29-33.

VALLORTIGARA, G., REGOLIN, L., BORTOLOMIOL, G. and TOMMASI, L. (1996). Lateral asymmetries due to preferences in eye use during visual discrimination learning in chicks. Behav. Brain Res. 74: 135-143.

VANDENBERG, L.N. (2012). Laterality defects are influenced by timing of treatments and animal model. Differentiation 83: 26-37.

VANDENBERG, L.N., BLACKISTON, D.J., REA, A.C., DORE, T.M. and LEVIN, M. (2014). Left-right patterning in Xenopusconjoined twin embryos requires serotonin signaling and gap junctions. Int. J. Dev. Biol. 58: 799-809.

VANDENBERG, L.N., LEMIRE, J.M. and LEVIN, M. (2012). Serotonin has early, ciliaindependent roles in Xenopus left-right patterning. Dis Model Mech 6: 261-268.

VANDENBERG, L.N., LEMIRE, J.M. and LEVIN, M. (2013). It's never too early to get it Right: A conserved role for the cytoskeleton in left-right asymmetry. Comm. Int. Biol. 6: e27155.

VANDENBERG, L.N. and LEVIN, M. (2009). Perspectives and open problems in the early phases of left-right patterning. Sem. Cell. Dev. Biol. 20: 456-463.

VANDENBERG, L.N. and LEVIN, M. (2010a). Consistent left-right asymmetry cannot be established by late organizers in Xenopus unless the late organizer is a conjoined twin. Development 137: 1095-1105.

VANDENBERG, L.N. and LEVIN, M. (2010b). Far from solved: A perspective on what we know about early mechanisms of left-right asymmetry. Dev Dyn239:3131-3146.

VANDENBERG, L.N. and LEVIN, M. (2012). Polarity proteins are required for left-right axis orientation and twin-twin instruction. Genesis 50: 219-234.

VANDENBERG, L.N. and LEVIN, M. (2013). A unified model for left-right asymmetry? Comparison and synthesis of molecular models of embryonic laterality. Dev. Biol. 379: 1-15.

VERMOT, J. and POURQUIE, O. (2005). Retinoic acid coordinates somitogenesis and left-right patterning in vertebrate embryos. Nature 435: 215-220.

WADDINGTON, C.H. (1937). The dependence of head curvature on the development of the heart in the chick embryo. J. Exp. Biol. 14: 229-231.

WAKAMATSU, M., YAMAGATA, T., NAMIKAWA, T. and MIZUTANI, M. (2000). Hereditary persistent right oviduct in the chicken PNP/DO line. Poultry Sci. 79: 1075-1081.

WANG, S., YU, X., ZHANG, T., ZHANG, X., ZHANG, Z. and CHEN, Y. (2004). Chick $\mathrm{Pcl} 2$ regulates the left-right asymmetry by repressing Shh expression in Hensen's node. Development 131: 4381-4391.

WELSH, I.C., THOMSEN, M., GLUDISH, D.W., ALFONSO-PARRA, C., BAI, Y., MARTIN, J.F. and KURPIOS, N.A. (2013). Integration of left-right Pitx2 transcription and Wnt signaling drives asymmetric gut morphogenesis via Daam2. Dev. Cell 26: 629-44.

WILTING, J. and HAGEDORN, M. (2011). Left-right asymmetry in embryonic development and breast cancer: common molecular determinants? Curr. Med. Chem. 18: 5519-5527.

WOODRUFF, R. and TELFER, W. (1980). Electrophoresis of proteins in intercellular bridges. Nature 286: 84-86.

XU, J., VAN KEYMEULEN, A., WAKIDA, N.M., CARLTON, P., BERNS, M.W. and
BOURNE, H.R. (2007). Polarity reveals intrinsic cell chirality. Proc Natl Acad Sci USA 104: 9296-9300.

YOKOUCHI, Y., VOGAN, K., PEARSE, R. and TABIN, C. (1999). Antagonistic signaling by Caronte, a novel Cerberus-related gene, establishes Left-Right asymmetric gene expression. Cell 98: 573-583.

YOKOYAMA, T., COPELAND, N.G., JENKINS, N.G., MONTGOMERY, C.A., ELDER F.F. and OVERBEEK, P.A. (1993). Reversal of left-right asymmetry: a situs inversus mutation. Science 260: 679-682.

YOSHIOKA, H., MENO, C., KOSHIBA, K., SUGIHARA, M., ITOH, H., ISHIMARU, Y., INOUE, T., OHUCHI, H., SEMINA, E.V., MURRAY, J.C. et al., (1998). Pitx2, a bicoid-type homeobox gene, is involved in a lefty-signaling pathway in determination of left-right asymmetry. Cell 94: 299-305.

YOST, H.J. (1990). Inhibition of proteoglycan synthesis eliminates left-right asymmetry in Xenopus laevis cardiac looping. Development 110: 865-874.

YOST, H.J. (1991). Development of the left-right axis in amphibians. Ciba Foundation Symp. 162: 165-76; discussion 176-181.

YUAN, F., ZHAO, L., WANG, J., ZHANG, W., LI, X., QIU, X.B., LI, R.G., XU, Y.J., XU, L., QU, X.K. et al., (2013). PITX2c loss-of-function mutations responsible for congenital atrial septal defects. Int. J. Med. Sci. 10: 1422-1429.

YUAN, S. and SCHOENWOLF, G.C. (1998). De novo induction of the organizer and formation of the primitive streak in an experimental model of notochord reconstitution in avian embryos. Development 125: 201-213.

YUAN, S. and SCHOENWOLF, G.C. (2000). Islet-1 marks the early heart rudiments and is asymmetrically expressed during early rotation of the foregut in the chick embryo. Anatomical Rec. 260: 204-207.

YUE, X., SCHULTHEISS, T.M., MCKENZIE, E.A. and ROSENBERG, R.D. (2004). Role of heparan sulfate in dextral heart looping in chick. Glycobiology 14: 745-755.

ZAMIR, E.A., SRINIVASAN, V., PERUCCHIO, R. and TABER, L.A. (2003). Mechanical asymmetry in the embryonic chick heart during looping. Ann Biomed Eng 31: 1327-1336.

ZHANG, Y. and LEVIN, M. (2009a). Left-right asymmetry in the chick embryo requires core planar cell polarity protein Vangl2. Genesis 47: 719-728.

ZHANG, Y. and LEVIN, M. (2009b). Particle tracking model of electrophoretic morphogen movement reveals stochastic dynamics of embryonic gradient. Dev Dyn 238: 1923-1935.

ZHAO, D., MCBRIDE, D., NANDI, S., MCQUEEN, H.A., MCGREW, M.J., HOCKING, P.M., LEWIS, P.D., SANG, H.M. and CLINTON, M. (2010). Somatic sex identity is cell autonomous in the chicken. Nature 464: 237-242.

ZHU, L., BELMONT, J.W. and WARE, S.M. (2006). Genetics of human heterotaxias. Eur J Hum Genet 14: 17-25.

ZHU, L., MARVIN, M., GARDINER, A., LASSAR, A., MERCOLA, M., STERN, C. and LEVIN, M. (1999). Cerberus regulates left-right asymmetry of the embryonic head and heart. Curr. Biol. 9: 931-938.

ZILE, M.H., KOSTETSKII, I., YUAN, S., KOSTETSKAIA, E., STAMAND, T.R., CHEN, Y. and JIANG, W. (2000). Retinoid signaling is required to complete the vertebrate cardiac left/right asymmetry pathway. Dev. Biol. 223: 323-338. 


\section{Further Related Reading, published previously in the Int. J. Dev. Biol.}

Left-right asymmetry specification in amphioxus: review and prospects

Vladimir Soukup

Int. J. Dev. Biol. (2017) 61: 611-620

https://doi.org/10.1387/ijdb.170251vs

Heart formation and left-right asymmetry in separated right and left embryos of a newt Kazuhiro Takano, Yuzuru Ito, Shuichi Obata, Tsutomu Oinuma, Shinji Komazaki, Hiroaki Nakamura and Makoto Asashima

Int. J. Dev. Biol. (2007) 51: 265-272

https://doi.org/10.1387/ijdb.072270kt

Xenopus neurula left-right asymmetry is respeficied by microinjecting TGF-beta5 protein Kazue Mogi, Madoka Goto, Eri Ohno, Yoshitaka Azumi, Shigeo Takeuchi and Ryuji Toyoizumi Int. J. Dev. Biol. (2003) 47: 15-29

http://www.intjdevbiol.com/web/paper/12653248

The roles of activin and follistatin signaling in chick gastrulation

M Levin

Int. J. Dev. Biol. (1998) 42: 553-559

http://www.intjdevbiol.com/web/paper/9694626

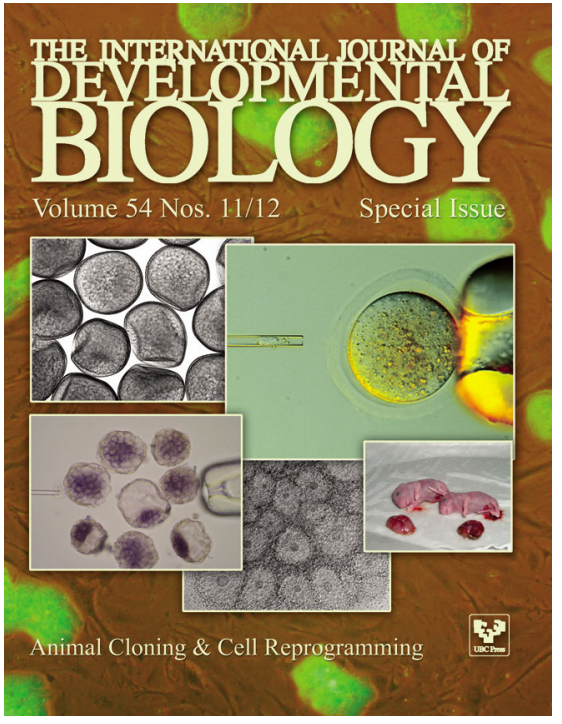

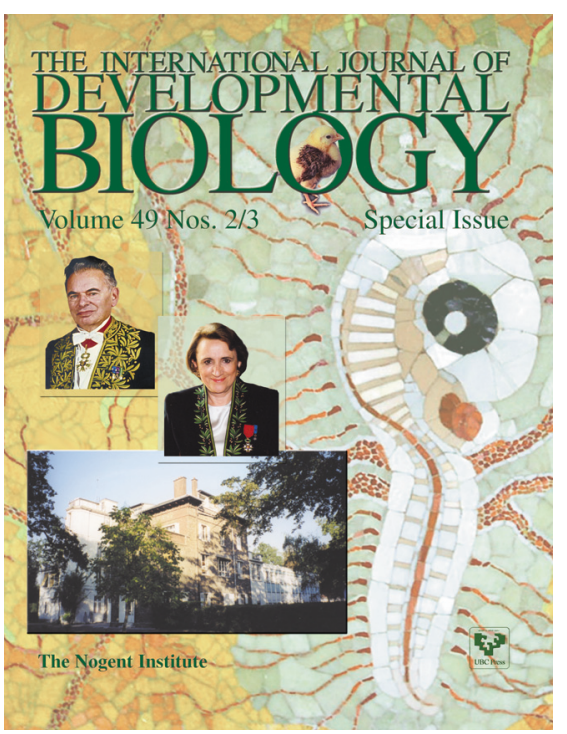

5 yr ISI Impact Factor $(2016)=2.421$
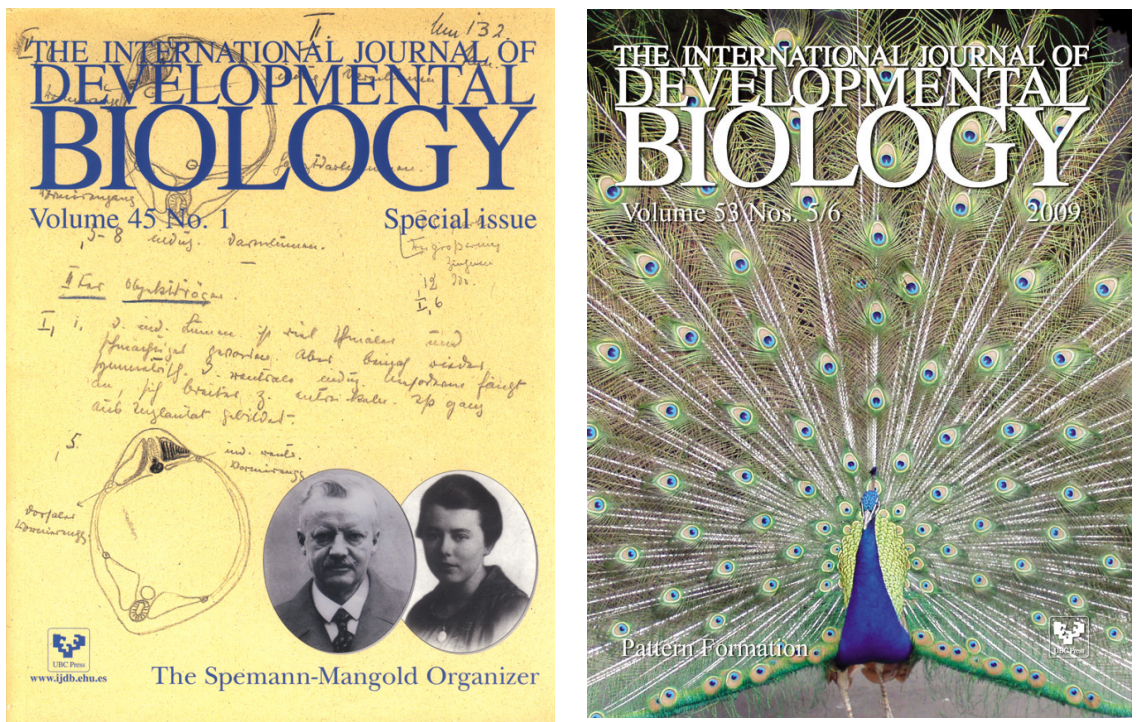